\title{
THE PAPERLESS LETTER OF CREDIT AND RELATED DOCUMENTS OF TITLE
}

\author{
BORIS KOZOLCHYK*
}

\section{INTRODUCTION}

Computers, telephones, and artificial satellites have made the 24-hour global financial marketplace a reality. At any hour of the day, a trader of goods, services, or financial undertakings can, by using computers linked with telephone lines, microwave dishes, or artificial satellites, engage in transactions to sell, buy, lease, assign, or borrow instantaneously with another trader, no matter how distant. Bank letters of credit and guarantees occupy an important corner of this global marketplace. And while most letter-ofcredit communications between banks and beneficiaries are still paper-based, communications among banks themselves are in very large measure paperless. According to reliable estimates, seventy-five percent of banks' requests for other banks' issuance, advice, confirmation, or negotiation of credits are sent electronically; the remainder are sent by letter. ${ }^{1}$

Copyright $\odot 1992$ by Law and Contemporary Problems

- Professor of Law, University of Arizona; on leave as Director of the National Law Center for Inter-American Free Trade; U.S. Representative to the International Chamber of Commerce for the Revision of the Uniform Customs and Practice for Documentary Credits; U.S. Delegate to the United Nations Commission on International Trade Law.

This article is dedicated to Bernard S. Wheble, this century's most influential draftsman of letterof-credit customary law, a man of vision, integrity, and devotion to good causes, including true friendship. The writer is grateful to the Law College Association of the University of Arizona for research grant support and to Dan Taylor, Executive Director of the United States Council on International Banking ("USCIB"), and Charles del Busto, Chairman of the Banking Commission of the International Chamber of Commerce for many helpful comments and suggestions, especially on the description of banking practices. The section on Society for Worldwide Interbank Financial Telecommunications ("SWIFT") procedures has benefitted greatly from explanations provided by John Pritt, SWIFT's Standard Manager, and from materials provided by Sandra Bleich, SWIFT's Director of Corporate Standards, and Alan Bloodgood, Joseph Nielsen, Maryann Pizzulo, and Angelo Schiraldi of the Letter of Credit Committee of the USCIB. The section on applicant-initiated electronic letters of credit has drawn extensively on the information supplied by Vincent M. Maulella, of Manufacturers Hanover Trust, and Scott McCoy, of Chase Manhattan Bank. The section on the interaction between article $4 \mathrm{~A}$ of the Uniform Commercial Code and reimbursement practices reflects discussions with James McGinley and Arthur G. Lloyd of Citibank. Terry J. Mitchell, Representative of the British Bankers Association to the Banking Commission of the International Chamber of Commerce ("ICC"), provided useful information on the standardization of EDIFACT letter-of-credit messages. Professor James E. Byrne, of George Mason University School of Law, and Bernard Wheble, Honorary Chairman of the Banking Commission of the ICC, were kind enough to read this manuscript and offer helpful suggestions, as did Billie Kozolchyk. Peter Matiatos, Esq., rendered valuable editorial assistance. The writer alone, however, bears responsibility for mistakes.

1. Presentation by Sandra Bleich, USCIB Annual Conference (Oct 13, 1990). It should be noted that while SWIFT is used almost invariably for communicating commercial letters of credit, it is not as universally used for bank guarantees and even less so for standby letters of credit. Standby letters of credit usually require a considerable amount of "free" or nonformatted text, and are 
Similarly, the number of applicants who are linked to computer systems that enable them to tailor the terms and conditions of their credits and telecommunicate them to the issuing banks has also increased sharply. At one large regional bank, the increase over the last five years has been approximately 500 percent. ${ }^{2}$ Finally, an increasing number of letters of credit issued by both banks and nonbanks are being communicated directly by issuers to the beneficiaries' computers, ${ }^{3}$ and other letters of credit (still a small number) are communicated to beneficiaries through nonbanking "value added networks" or via bank proprietary systems.

Despite the large volume and worldwide scope of these paperless transactions, their "rules of traffic" and formal requirements have yet to be validated legislatively, administratively, or judicially. Thus no positive law exists, for example, on the time when an issuing bank's promise of payment or of reimbursement becomes irrevocably binding on an issuer, or on the formalities of the "operative credit instrument" (including the need for a writing and signature), or on interbank liability for negligent, delayed, or fraudulent transmissions. Rules do exist, however, for the operation of the Society for Worldwide Interbank Financial Telecommunications ("SWIFT"), a banking telecommunications network whose letter-of-credit transactions will be described in this article. Moreover, the same banks that now send paperless messages to one another adhere universally to the Uniform Customs and Practice for Documentary Credits ("UCP"). ${ }^{5}$ But the interaction between the UCP and SWIFT rules is not entirely harmonious, and conflicts are similarly apparent between the recently enacted article $4 \mathrm{~A}$ of the Uniform Commercial Code ("UCC") and the practices of banks engaged in prepaying, paying, or reimbursing letters of credit.

In short, the time is now ripe for a normative analysis of paperless letters of credit that will categorize the various transactions and delineate the boundaries and relative standing of the competing sets of rules. This analysis should also suggest when an official legal rule is needed and what its thrust should be.

usually communicated directly by the issuing bank to the beneficiary. Yet, while this is true for national standbys, international standbys are often telecommunicated.

2. Telephone interview with Maryann Pizzulo, of NCNB Bank (May 1, 1991).

3. Id.

4. See SWIFT User Handbook version 1.0, 89/4. Throughout the remainder of this article, "SWIFT User Handbook" and "SWIFT rules" will be used interchangeably. Unless otherwise specified, the version of the Handbook cited here will be used throughout this article. Occasionally, where SWIFT merely comments on a procedure without setting forth a rule, the reference will be to the Handbook chapter and page.

5. The UCP are the most widely observed customary banking rules in the world. They are promulgated by the International Chamber of Commerce, headquartered in Paris, France and are revised from time to time to keep up with technological, business, and legal developments. The present revision is from 1983 and is found in Publication Number 400 of the International Chamber of Commerce. References to the UCP throughout this article will be to this publication. Publication Number 500 is now almost complete and will probably come into effect at the end of 1992 . For a discussion of the normative value of the UCP as a source of letter-of-credit law, see Boris Kozolchyk, Letters of Credit, 9 Intl Encyclopedia Comparative L 5-15 through 5-36 (J. C. B. Mohr, 1979). 
This article will undertake such an analysis together with a detailed description of customary practices in the United States and, where appropriate, elsewhere as well. Furthermore, since the time is nearing when paperless documents will be presented to banks in purported compliance with paperless credits, this article will explore-albeit in lesser detail-the "presentation" of paperless bills of lading in fulfillment of a condition of payment.

\section{Paperless Credit Promises}

\section{A. The SWIFT Letter of Credit}

1. EDI as the Technological Basis of SWIFT. In 1974, most letters of credit were communicated by mail, cable, or telex. Article 4 of the 1974 revision of the UCP reflected this practice by listing "cable, telegram or telex" as the means with which to "instruct" letters of credit. ${ }^{6}$ The 1983 UCP, however, replaced the reference to "cable, telegram or telex" with "teletransmission," thereby acknowledging a remarkable shift in banking practice. In less than a decade, the bulk of interbank letter-of-credit messages switched from paper communications to teletransmissions. ${ }^{7}$ A closer look at the evolution of the format of letters of credit reveals that the shift to an electronic format started many years earlier with the introduction of cabled and telexed letters of credit. A "tested" telex contained many of the same elements-although not the same technology-as the current electronic letter of credit. Its "authenticator" key acted as the means to verify the authenticity and integrity of the message, much as SWIFT's algorithm does today.

6. Article 4 of the 1974 UCP states: "When an issuing bank instructs a bank by cable, telegram or telex to advise a credit, and intends the mail confirmation to be the operative credit instrument, the cable, telegram or telex must state that the credit will only be effective on receipt of such mail confirmation."

7. Article 12 of the 1983 UCP reads as follows:

(a) When an issuing bank instructs a bank (advising bank) by any teletransmission to advise a credit or an amendment to a credit, and intends the mail confirmation to be the operative credit instrument, or the operative amendment, the teletransmission must state "full details to follow" (or words of similar effect), or that the mail confirmation will be the operative credit instrument or the operative amendment. The issuing bank must forward the operative credit instrument or the operative amendment to such advising bank without delay.

(b) The teletransmission will be deemed to be the operative credit instrument or the operative amendment, and no mail confirmation should be sent, unless the teletransmission states "full details to follow" (or words of similar effect) or states that the mail confirmation is to be the operative credit instrument or the operative amendment.

When consulted by the Austrian National Committee on the precise meaning of "teletransmission," the Commission on Banking Technique and Practice of the ICC ("Banking Commission") replied that "teletransmission" did not include phone communications but did include instructions received by telefax. Meeting of April 23, 1985, ICC Doc 470/444, 470/452 (1985). As a consequence, a letter of credit transmitted by telefax bearing the correct test key constituted an operative credit instrument for purposes of article 12b. See Opinion R99, ICC Doc 434 (1984-1986). 
SWIFT was created in 1973 as a bank-owned, Belgian, not-for-profit cooperative organization. Its purpose was to facilitate the transmission of bank-to-bank financial transaction messages. ${ }^{8}$ An experienced American banker estimated the cost of sending a letter of credit by telex in the early 1980 s to be between ten and twenty-five dollars as compared to 17.5 Belgian francs or approximately fifty cents had the same message been sent by SWIFT. ${ }^{9}$ This saving was made possible by the adoption of a method of electronic communication known as Electronic Data Interchange ("EDI"). EDI's application to financial, bank-to-bank messages has lowered costs by requiring that the messages be structured in uniform fashion, including standardized elements for the allocation of message space and for the text of the message itself. This emphasis on uniformity and standardization has made it possible for the computers communicating through EDI to exchange and process data without rekeying the data. ${ }^{10}$

EDI borrowed from the printed "boilerplate" paper forms the notion that the location of the data conveys a specific meaning and is, therefore, an integral part of the message. For example, a number placed in the quantity column of an invoice conveys a meaning quite different from the meaning conveyed by the same number placed in the price column. A reader familiar with such a paper format will thus automatically look to the quantity column for information on the size of the shipment and to the price column for information on its cost. In EDI jargon, then, a "transaction set" contains the electronic directions or location "lines" that designate the proper place in which data must appear. ${ }^{11}$ These lines reflect the practices of parties dealing with specific EDI messages, and once the practice (or agreement on what the practice should be) is sufficiently widespread, an EDI standards committee

8. For excerpts from SWIFT's "General Terms and Conditions" as well as "Articles of Association," see Herbert F. Lingl, Risk Allocation in International Electronic Fund Transfers: Chips and Swift, 22 Harv Intl L J 621, 622-23 nn4 \& 7 (1981). Robert Winder attributes SWIFT's uniqueness to the fact that it was a joint-owned cooperative at a time when "the ambitious banks were already spraying computing power across the world in an attempt to establish a market advantage." Robert Winder, Too SWIFT for Comfort, Euromoney 55 (Jan 1985). On Swift's growing role, see Ezra U. Byler \& James C. Baker, SWIFT: A Fast Method to Facilitate International Financial Transaction, $17 \mathrm{~J}$ World Trade L 458, 461 (1983). See also Note, The Courts and CHIPS SWIFT E् FEDWIRE: A Proposal for Filling the Regulatory Gap, 2 Intl Prop Inv J 271 (1984) (authored by Lawrence S. Drexler).

9. Dan Taylor stated that one major bank calculated the cost per message to be at least onefifth the cost of sending a message without SWIFT. Interview with Dan Taylor, Executive Director of USCIB (Jan 10, 1990). USCIB is an umbrella organization, headquartered in New York City at the World Trade Center, that represents the interests of approximately 400 banks involved in international banking transactions.

10. See United Nations Commission on International Trade Law, Electronic Data Interchange, Preliminary Study of Legal Issues Related to The Formation of Contracts for Electronic Means 5 (May 18, 1990) (report of Sectretary General) (A/CN.9/333) ("UNCITRAL 1990"). See also American Bar Association, Electronic Messaging Services Task Force, The Commercial Use of Electronic Data Interchange-A Report, 45 Bus L 1647, 1650 (1990) ("ABA Report"). More generally, see Benjamin Wright, EDI and American Law-A Practical Guide (Electronic Data Interchange Assn, 1989).

11. For the remainder of this section, I will borrow from the description of the EDI formulation of message process in a student paper by Douglas Morrison, The Statute of Frauds Online: Can a Computer Sign a Contract for the Sale of Goods?, 14 Geo Mason L Rev (forthcoming Spring 1992). 
writes the rules for each transaction set, including the relevant glossaries or dictionaries. ${ }^{12}$

As a result of standardizing the placement and the contents of the text, a typical EDI transaction set contains segments that convey the data pertinent to the message (referred to as "data" segments) and segments that control their location, safety, and integrity (referred to as "control" segments). The following English translation of an EDI purchase order illustrates the manner in which the data and control segments interact: ${ }^{13}$

(1) "This is a purchase order."

(This message, which can act as both a control and data segment, can be spelled out or summarized using an assigned standardized message type and number.)

(2) "This purchase order belongs to this particular transmission."

(EDI creates and enters the number assigned to the transaction set in question. This is a control segment.)

(3) "This purchase order has a designated number of segments in it."

(EDI calculates and enters the number of segments in this transaction set. This is a control segment.)

(4) "The number of items ordered in this purchase order is . . ."

(EDI calculates how many items this purchase order contains. This is

a control segment.)

(5) "This is item $1 \ldots$..."

(This is the first data segment as it specifies the stock number of the item(s) ordered.)

(6) "The quantity of item 1 ordered is ...."

(This is a data segment.)

(7) "The price we are willing to pay for item 1 is ...."

(This is a data segment.)

It is noteworthy that the transition in some control-to-data segments (as among segments (1), (2), (4), and (5)) is almost imperceptible. An equally subtle transition occurs when the rules that govern the use of the EDI as a communication medium give way to those that govern the legal consequences of the EDI message. Once a given transaction set has been properly labeled or identified, as in segment (1) above, and the appropriate segments have been inserted, the message becomes a distinct obligational unit and will be acted upon by the recipient as if it were, for example, a standard paper-based purchase order or a request for the confirmation of an irrevocable letter of credit. Segment (1) thus plays the key role in bringing about the transition from an electronic medium of communication to a legally binding message. The "magic" words (or code) are "this is a purchase order" or "this is a request

12. In the United States, the EDI Standards Committee operates under the auspices of the Data Interchange Standards Association, located in Alexandria, Virginia.

13. The sequel in the principal text is based largely on the illustration provided by Morrison, The Statute of Frauds Online (cited in note 11). 
for confirmation of an irrevocable letter of credit," for these words imply that the message entails all the consequences normally attributable to an equivalent paper-based message. ${ }^{14}$

2. EDI Rules: Medium and Transaction. EDI transactional rules are concerned with the binding effect of a message upon an issuer, a recipient, and any other parties who receive or rely upon the message. Where documentary credits are concerned, the UCP are the universally observed transactional rules. In contrast, EDI medium rules address the manner in which standardized electronic messages have to be prepared, entered, sent, carried, received, acknowledged, and protected by senders, recipients, carriers, and other intermediaries when communicating effectively and efficiently. As such, medium rules are rules of diligence in communicationsrelated conduct.

Given the importance that EDI places upon standardization, it is only natural that banks should subject themselves to SWIFT's standardized procedures. Other sources of EDI rules likely to be considered by banks and nonbanks when communicating with each other are the Model Agreement for EDI trading partners proposed by the Electronic Messaging Services Task Force of the American Bar Association ("ABA Model Agreement") ${ }^{15}$ and the Uniform Rules of Conduct for Interchange of Trade Data by Teletransmission ("UNCID"). ${ }^{16}$

The ABA Model Agreement was designed for purchase and sale transactions, and it contains both medium and transactional rules. One of its most important transactional rules replaces the traditional "mailbox rule" of communications inter ausentes with one of receipt: "receipt, and not transmission, determines the legal effect of any message transmitted by EDI and ... verification of the transmission is a mandatory element." 17 In

14. As will be discussed in connection with the problems of automatic incorporation of the UCP to paperless letter-of-credit messages, many bankers feel that the mere labeling or identification of the message is insufficient to make it an obligational unit, especially when it reaches a non-network party, such as the beneficiary of the documentary credit. On this point, see Part I.C.1.

15. See ABA Report (cited in note 10).

16. UNCID was adopted by the ICC Executive Board at its 5 lst Session in Paris (Sept 22, 1987), as ICC Publication N452 (Jan 1988). A number of influential intergovernmental and nongovernmental organizations contributed to UNCID. ICC Publication 452 at 6 lists the following: United Nations Commission on International Trade Law ("UNCITRAL"); Special Programme on Trade Facilitation of the United Nations Conference on Trade and Development ("UNCTAD/FALPRO"); Working Party on Facilitation of International Trade Procedures of the United Nations Economic Commission for Europe (“UN/ECE”); Customs Cooperation Council ("CCC"); Organization for Economic Co-Operation and Development ("OECD"); Commission of the European Communities ("EC"); International Organization for Standardization ("ISO"); European Insurance Committee ("CEA"); European Council of Chemical Industries Federation ("CEFIC"); Organization for Data Exchange via Teletransmission in Europe ("ODETTE"); Regional and national trade facilitation organizations such as NORDIPRO (the originator of the UNCID concept), FINPRO, NCITD (of the United States), SIMPROFRANCE, and SITPRO (of Great Britain).

17. ABA Report at 1667 (cited in note 10). The justification offered by the ABA Task Force is that the context of the mailbox rule is that of "delayed media" such as mailed writings in which none of the parties has the ability to verify receipt of the message in a timely fashion. By contrast, the $A B A$ 
addition, the ABA Model Agreement imposes upon the recipient-offeree the obligation "upon proper receipt, to promptly and properly transmit in return a message verifying receipt of the original [d]ocument."18 This verification has its own format called a "functional acknowledgment."19 Failure to provide this functional acknowledgment is a violation of the model agreement "for which the receiving party may be liable in damages."20

UNCID is a less ambitious set of medium rules. It expressly disclaims application to the underlying transaction, to which it refers as the "substance of the trade data transfers." 21 It prescribes rules of conduct for the parties to an EDI transmission, but solely to attain the most effective possible communication of the message. UNCID rules are couched in didactic, nonmandatory language and leave the determination of the legal consequences of the transmission to official law. Thus the parties are urged to check the correctness of the transmission and reception, ${ }^{22}$ and are provided with a list of message components that includes the identities of sender and recipient and the means of verifying the formal completeness and authenticity of the transfer. ${ }^{23}$

Unlike the ABA Model Agreement, UNCID does not specify the moment of effectiveness or "establishment" of the sender's obligation and leaves the acknowledgment of receipt to the parties' agreement. ${ }^{24}$ Moreover, instead of specifying the remedial consequences of a recipient's inaction, UNCID advises the recipient that he will not be authorized to act on the message until he has complied with the sender's request of verification. The studious avoidance of remedial language and the determination to stay within the confines of medium rules is apparent in one of UNCID's key provisions: ${ }^{25}$

If the sender has not received the stipulated acknowledgement within a reasonable or stipulated time, he should take action to obtain it. If despite such action, an acknowledgement is not received within a further period of reasonable time, the sender should advise the recipient accordingly by using the same means as in the first transfer or other means if necessary and, if he does so, he is authorized to assume that the original transfer has not been received.

3. The SWIFT Network. A SWIFT message originates from a network userfor example, the bank issuing the letter of credit-and is communicated to the

\footnotetext{
Task Force relied on section 64 of the Restatement of the Law of Contracts, Restatement (Second) of Contracts $\S 64$ (1981), which "specifically acknowledges the use of technology in communication in the form of telephone or other medium of substantially instantaneous two-way communication and sets forth the principle that communications using those technologies are governed by the same principles that apply when the parties are in the presence of each other." ABA Report at 1666-67 (cited in note 10) (citations omitted).

18. ABA Report at 1669 (cited in note 10).

19. Id.

20. Id at $\mathbf{1 6 7 0}$

21. See UNCID art 1 .

22. See id art 5 .

23. Id art 6

24. Article 7(a) of UNCID states: "The sender of a transfer may stipulate that the recipient should acknowledge receipt thereof...."

25. Id art 7(b)
} 
nearest SWIFT access point, one of which is located within most member countries. From the SWIFT access point, the message is routed to the regional processor, where validation of the message is performed. From the regional processor, the message is routed to the main switching or operating center. ${ }^{26}$ From the operating center, the message is routed along a reverse path to the receiving bank-that is, from the operating center, through the regional processor, through the SWIFT access point, to the receiving bank. The technology of message switching requires the ability to receive the electronic message, store it until the proper outgoing circuit and stations are available, and then retransmit it toward its destination. Computers are often used to perform the switching function.

Since SWIFT messages are transmitted on SWIFT's own dedicated telephone and international data transmission lines (referred to in SWIFT's rules as PTTs), ${ }^{27}$ they arrive at the receiving banks almost instantaneously. SWIFT, unlike fund transfer systems such as the Clearing House Interbank Payment System ("CHIPS"), is only a medium for the transmission of financial messages and does not effect settlements of letters of credit or other types of indebtedness among the issuing and receiving banks-that is, SWIFT does not serve as a clearinghouse. Thus in CHIPS, the computer tabulates the debits and credits of each participating bank and at the end of each day reports their individual net balances. ${ }^{28}$ In SWIFT, however, the settlement of letter-of-credit transactions is left to the participating banks' separate arrangements, with each bank debiting or crediting the other bank's "nostro" or "vostro" account to reflect the completion of each transaction. ${ }^{29}$ Currently, close to 2,000 banks and other financial institutions in seventy countries and 3,000 destinations worldwide rely on SWIFT's global

26. SWIFT currently has two operating centers-one located in Zouterwoude in the Netherlands, and the other in Culpepper, Virginia. This information and the preceding description of the routing process was provided by Mr. John Pritt, Standards Manager for SWIFT, in a telefaxed message dated May 3, 1991 ("Pritt Letter") (on file with the Documentation Center of the University of Arizona College of Law). Information was also provided by Carl Brickman, former North American area manager of SWIFT, in a telephone interview April 11, 1990 ("Brickman Interview").

27. A "dedicated line" is a communication line whose sole purpose is for the quick transfer of computer data for the exclusive use of an individual entity or trade group. These lines can be leased from the telephone company, or they can be part of a private communications network. Line dedication can result in cost savings and in an increased level of security. SWIFT's dedicated lines usually carry messages by what is known as "Packet Switching." Packet switching is designed for transmission of messages in a fixed (usually small) number of characters, as opposed to a transmission of messages of indeterminate length. The communication channels that carry the packets are connected only for the duration of the packet's transmission. Packet switching, therefore, can be very economical and requires terse messages and standardized transmission procedures. This feature explains SWIFT's continuous emphasis on reducing the length of its messages. On dedicated lines, see Webster's New World Dictionary of Computer Terms 98 (3d ed 1988) ("Webster's").

28. See note 91 for Judge Broderick's description of a typical CHIPS transaction.

29. A nostro account in banking parlance means the foreign currency account that the bank effecting a transfer of funds has with its correspondent bank. Thus a U.S. bank A transferring letterof-credit funds to a French bank B may instruct the latter to debit A's French franc nostro account. Conversely, a vostro account refers to the U.S. dollar account held with A by B. On this procedure, see Note, New SWIFT Rules on the Liability of Financial Institutions for Interest Losses Caused By Delay in International Fund Transfers, 13 Cornell Intl L J 311,312 (1980) (authored by David W. Ambrosia). 
telecommunications network to transmit more than a million messages a day, many of which involve letters of credit and bank guarantees. ${ }^{30}$

\section{Components of the SWIFT Letter-of-Credit Message; The Self-Sufficient Obligational} Unit. SWIFT's success is due, among other reasons, to its development of comprehensive and uniform standards for the formulation and communication of banking financial messages. ${ }^{31}$ The system has been developed by creating certain message types, each of which corresponds to a different SWIFT transaction. At the present time, SWIFT has nine message types, and English is the lingua franca for the formulation of SWIFT's messages. When drafting a letter-of-credit message, an issuing bank usually includes certain standard English language terms such as "irrevocable, documentary credit," "c.i.f" or "f.o.b," "on board, no transhipment bills of lading," and "payable to any drawers or bona fide holders of drafts." Once the appropriate terms are selected, SWIFT software translates the terms into mathematical symbols and compresses, encrypts, and, where required, authenticates the message.

The message-as does any other EDI message-capsulizes the obligational language and tells the recipient, "This is the issuance of a documentary credit" (Message Type 700/701), "This is a pre-advice of a documentary credit" (Message Type 705), "This is an advice of a third bank's documentary credit" (Message Type 710/711), or "This is a transfer of a documentary credit" message. The binding nature as well as the scope of the sender's obligation differ from message to message. Thus, if the message of issuance of an irrevocable credit binds the issuer and contains all the terms and conditions of the documentary credit, the pre-advice message provides only a nonbinding brief description of the credit with an indication that full details will follow. If the advice of a third bank's documentary credit merely notifies the receiver of the terms of the credit without engaging the advising bank's liability, however, the message of transfer binds its issuer to reimburse the bank that made the credit available in whole or in part to the transferee or second beneficiary of the credit.

Some SWIFT messages do more than communicate a binding or nonbinding promise; they are the very performance promised in the previously or concomitantly issued message. For example, when an issuer of Message Type 740 authorizes reimbursement of claims for payments or negotiations, he performs what he promised in his message of issuance and request for negotiation or payment. Thus, on the whole, SWIFT letter-ofcredit messages can be regarded as self-sufficient obligational units in the sense that neither the issuance of a letter of credit nor the requests or authorizations for its advice, confirmation, negotiation, or payment is the result of bilateral contracts between the issuing bank and the recipient(s) of

30. See SWIFT Standards, a Product Portfolio.

31. The Payments Working Group, other groups within SWIFT, and member banking associations periodically review and create the different segments of data that create a SWIFT. 
the SWIFT message. The recipient of a SWIFT letter-of-credit message does not need to signify his acceptance of the request for advice or of the authorization for negotiation or payment. He must only comply with the request or perform the authorized act, and he will be entitled to the issuer's reimbursement. Furthermore, the fact that the paperless credit promise and its performance are often issued either simultaneously or within a very short time span should be noted because, as will be discussed below in connection with the legal nature of the paperless credit, such immediate liquidity is usually associated only with the receipt of money or of highly "monetized" promises.

a. Security devices. SWIFT relies on a complex set of security devices, some of which (such as authentication) have acquired considerable legal significance. These security devices have been sufficiently effective to prevent outsiders from breaking into the system. ${ }^{32}$ Some security devices ensure that the message received by the receiving bank is the same as that sent by the issuing bank. These devices include " $\log$ in" procedures, applicationselection procedures, message numbering, error checking, and control of access at processors and system control centers. ${ }^{33}$ SWIFT also retains records of transactions, including the full text of each message, and maintains a system $\log$ for a number of months. ${ }^{34}$

Other security features are also built into the layout of the SWIFT message. For example, an issuing bank must enter its address, that of the receiving bank, and the message type number. In payment messages, the amount and date when the funds are to be at the disposal of the receiver must also be entered. Finally, SWIFT relies upon encryption and authentication. To encrypt means to encode or scramble a message in such a way as to make it unintelligible without decoding or unscrambling, which is decryption. ${ }^{35}$ SWIFT encrypts all of its messages. ${ }^{36}$ When transmitting to the regional

32. According to the Pritt Letter (cited in note 26), no breaches of the system had been reported until May 1991.

33. See SWIFT Rule 22.1.1.

34. Id. Some of these security features-such as the "log in" procedures-depend upon acts by the users. Other security features are built into the messages-such as the highly uniform formats and the self-auditing capabilities. SWIFT messages are self-audited by devices such as "headers" and "trailers" to help detect message invalidity and extraordinary use patterns. The "header" is the part of the message that contains the information that directs the message to its destination and can be used in the authentication process. The "trailer" is a special data item located at the end of the message or the end of a list of items used to determine whether the message was sent according to the number of characters received as well as the presence of certain key words and addresses. Some trailers indicate whether the delivery of a message has been delayed for some reason or whether the receiving bank has received duplicate messages. A typical SWIFT message contains numerous trailers. On headers and trailers, see generally Webster's at 370 (cited in note 27); see also James V. Vergari, Latent Legal Repercussions in Electronic Financial Services and Transactions, 5 Comp L J 177, 202 (1984-85).

35. Encryption is the process of coding or garbling information so its true content and nature is masked from those who are unauthorized to see it. See Webster's at 132 (cited in note 27). Decryption is the process of decoding or degarbling information so its true content and nature is revealed to those who are authorized to see it. Id.

36. Pritt Letter (cited in note 26). 
processor, an issuing bank has the option of encrypting the message, thereby minimizing the possibility of alteration or interference. If the issuing bank encrypts the message, the regional processor first decrypts it and checks it for validity and then reencrypts it and sends it to the operating center, which in turn forwards it to the regional processor and SWIFT access point of the receiving bank. The message is decrypted only when it leaves the SWIFT network, ${ }^{37}$ although the receiving bank may decide to have the message reencrypted for use in further messaging.

The authentication of a message is effected by the use of an algorithm or mathematical formula that calculates the contents of a message from header to trailer. The authenticator key contains the algorithm. The issuing bank's computer-based terminal on its own-that is, not relying on a SWIFTsupplied device or software-computes the contents of the message and compiles a result based on the number of characters and data fields. At the regional processor, as part of the message validation process, SWIFT ascertains whether the message type requires authentication. If it does, SWIFT checks the authentication trailer. It is important to note that SWIFT does not check for more than the number of characters in the authenticator. Additional authentication checks are performed by the issuing and receiving banks themselves. ${ }^{38}$ The results arrived at by both the receiving and issuing banks must match. If they do not match, a fraudulent and unauthorized use of the system coupled with data manipulation may be occurring. ${ }^{39}$ Because of their large value and vulnerability, letter-of-credit messages (SWIFT Category 7) must all be authenticated.

b. Other components: system, category, group, type, field, and character. SWIFT's system of communication relies on an elaborate classification of messages and component parts. Each message belongs to a "category," a

37. Id; Brickman Interview (cited in note 26).

38. Pritt Letter (cited in note 26). SWIFT Rule 22.1.2.2 makes it clear that Swift users are responsible for the exchange of authenticator keys and for insuring the correct authentication of messages. SWIFT aids its users by providing them with an authenticating algorithm and by "checking that the authenticator is present in the specified categories of messages."

39. Although SWIFT has never been breached by unauthorized users, it changed its algorithm. The old algorithm required authenticator keys that were 16 characters long; this gave a fourcharacter authentication result. The new algorithm is 32 characters long and gives an eight-character authentication result. The prior algorithm was Data Encryption Standard ("DES") based. DES is a method of data protection developed by IBM and accepted by the National Bureau of Standards that uses a single "private key" to encrypt data. Webster's at 88 (cited in note 27). The new algorithm is not DES-based. This worries banks in the United States because they are not convinced that the new algorithm is as secure as the old algorithm even with the doubled authentication result. Despite the reservations of U.S. banks, the new algorithm was implemented during the second quarter of 1991.

Banks that use SWIFT are required to maintain individual authenticators for each of their correspondent banks. Many banks have requested that SWIFT manage the authenticator algorithms for the user banks as a separate business, and SWIFT may very well do so. SWIFT is currently contemplating the use of "Smart Cards" for password authentication in the login process, especially for the exchange of authenticator keys. Smart Cards provide computational ability; each card carries its own microprocessor. On these cards, see Donald I. Baker \& Roland E. Brandel, 2 The Law of Electronic Fund Transfer Systems 9-1, 9-2 (Warren, Gorham \& Lamont, 2d ed 1988). 
conception that is broad enough to include "system" messages ${ }^{40}$-that is, messages between a user and SWIFT, including the all-important “Undelivered Message Report" (Message Type 082). Within each category, there are "groups" of messages, such as " $73 n$ " for "advices" of Category 7 messages. Having been classified as a numerical group, any advice of a letter of credit will contain the same elements. Groups, in turn, are divided into types, each of which contains the data generally associated with a specific, commonly used message. Message Type 732, for example, advises that documents received with discrepancies have been taken up by the negotiating or paying bank. Its numbers indicate its affiliation with Category 7 and with Group 73n.41

Each message type contains data fields, which are discrete groups of characters placed in generally the same location as they would be if they were sections or segments in the paper-based documents used as models for each message type. ${ }^{42}$ The space of the message contained in each data field (or the number of characters per data field) is also allocated in a manner consistent with, or at least proportional to, the customary space allocation in paperbased credits or credit-related messages. It should be noted that in order to remain functional, cost effective, and secure, SWIFT imposes and abides by rigorous space limitations. Thus when an issuing bank transmits a SWIFT message, the regional processor will reject it if the issuer has exceeded the number of characters allotted to the field.

40. These system messages are designated with a 0 (zero) prefix, and each category bears its own number. For example, Category 7 covers letters of credit and bank guarantees.

41. SWIFT User Handbook, Standards 3-Trade Finance, 1.0 to 2-4 (1989). Category 7 has seven group messages and twenty-two message types. A message type has a set of standard information broken down into small units of information referred to as fields. A data field is "a single piece of information, the smallest unit normally manipulated by a data base management system." Webster's at 145 (cited in note 27). To illustrate, while a telephone directory can be regarded as a database, a telephone listing would be a record, and the telephone number is the data field.

42. Message Type 700 (the operative credit instrument of the letter-of-credit transaction) is divided into 34 fields and Message Type 701 into five additional fields. Each field of information is tagged by an assigned number in accordance with "field specifications." A field tag is merely an English language description of what the SWIFT field contains. A field specification is a detailed description of the field's scope. These specifications are numbered and coded, although the numbers are not always in sequential order. Whether the field specifications within a message are mandatory depends upon the nature of the information they contain. If, for example, the message type is Message Type 700 , a numbered field identifies the species of documentary credit being issued. Other fields identify the credit number, date of issue, date and place of expiry, applicant's bank, applicant's name or designation, beneficiary's name and designation, currency of issuance, description of the goods, type of shipment, and so on. Each of these fields is assigned a space in the letter-of-credit layout that contains a limited number of characters. If the data of the operative credit instrument conveyed by Message Type 700 exceed the maximum input message length, the additional data can be conveyed by Message Type 701 messages, as long as the total number of Message Type 701 messages does not exceed three. See SWIFT User Handbook ch 4 at 4.1 . At the present time, the total length of SWIFT messages (in both SWIFT I and SWIFT II versions) is 2,000 characters. Pritt Letter (cited in note 26). Each character corresponds to a letter of the alphabet. At the end of 1992 (the time when all SWIFT I users are expected to switch to SWIFT II), the letter-ofcredit message length may be increased to 10,000 characters. Id. This enlargement should facilitate the use of fields, such as "description of the goods" and "additional terms and conditions," whose size, at present, seem too small. 
5. Transmission Procedure. Banks usually assign the task of sending SWIFT messages to a designated computer or group of computers. Consequently, while the letter-of-credit text may be prepared in any computer, it must be transmitted internally to a computer that contains SWIFT software and an appropriate modem. As was described earlier, ${ }^{43}$ an issuing bank routes a message through the SWIFT access point to the regional processor. The regional processor acknowledges the message, which means not only that it has been received but also that it meets SWIFT standards of messaging and will be delivered as sent. This acknowledgment, therefore, presupposes that the issuing bank's message was authenticated and decrypted and that SWIFT assumes the obligation of delivery to the receiving bank (usually an advising or confirming bank in letter-of-credit transactions), while controlling the storage and retrieval of the message. ${ }^{44}$

SWIFT's control over each message and its ability to identify messages sequentially enable the receiving bank to detect a loss or duplication of the message. ${ }^{45}$ Though most messages are delivered within one to two minutes of being entered into the issuing bank's SWIFT-dedicated computer, if a message is detained and cannot be delivered during a given period, SWIFT automatically sends an "Undelivered Message Report" to the sending bank. ${ }^{46}$ The maximum amount of time delivery could take is approximately two hours. After a receiving bank receives the message, the receiving bank or a third bank can credit or pay a beneficiary on the specified pay date. ${ }^{47}$

Receiving banks are required to keep their computer terminals logged into the SWIFT system for at least seven hours on normal working days between 8 a.m. and 6 p.m. ${ }^{48}$ In order to use the system, a receiving bank must have a computer or group of computers equipped with SWIFT software, including

43. See text accompanying note 26 .

44. Brickman Interview (cited in note 26).

45. SWIFT requires that a receiver bank check each message sequentially as it arrives or in accordance with an output-sequence-number. See Byler \& Baker, $17 \mathrm{~J}$ World Trade $\mathrm{L}$ at 461 (cited in note 8). On network correspondents, see also Baker \& Brandel, 2 The Law of Electronic Fund Transfer Systems $\$ 29.02$ at 29-6 (cited in note 39 ).

46. The most common cause of undelivered messages is that the receiving bank is off-line and the message cannot be delivered. Brickman Interview (cited in note 26).

47. Since SWIFT has adopted the UCP's letter-of-credit terminology, the party requesting the transmission of a SWIFT message is referred to as the "applicant," the bank sending the message is referred to as the "issuing bank," the person entitled to draw on the letter of credit or bank guarantee is the "beneficiary," and the bank that advises the credit is the "advising" bank, as distinguished from a bank that adds its own confirmation, which is referred to as the "confirming" bank. Another bank frequently mentioned in SWIFT letter-of-credit messages is the "reimbursing bank," which authorizes the issuing bank to grant reimbursement of payment(s) or negotiation(s) under a documentary credit. Thus, advising, confirming, and reimbursing banks can all be "receiving" banks of SWIFT messages.

48. SWIFT Rule 21.3. This requirement allows banks from all over the world to send messages during their own business hours and still accommodate other countries' business hours. It also prevents backlogs because a SWIFT message must promptly be passed through to a designated receiver. If the communication lines are closed, the SWIFT message is required to wait until the lines open up. In such a case, the sending bank receives information on the undelivered message in the daily Undelivered Message Report. SWIFT software checks the message flow and identities of users logged on to the system; if the SWIFT software locates a terminal which does not log in within the designated period of time, then a report is sent to "oversight" personnel for corrective action. 
software to render the SWIFT message readable in "plain" or "safety" (individualized) paper formats. Once the receiving bank has received and checked the message, it must report to the issuing bank so that the latter can ascertain that its message was received.49 SWIFT-compatible software enables the receiving bank's clerk to convert the SWIFT message into a. customary paper-based letter of credit. Depending upon the nature of the message, it may be transcribed in whole or relevant part. In the case of partial transcription, the transcribed text will be typed or printed on the receiving bank's stationery, together with whatever additional text the receiving bank inserts on its own. Upon conversion, then, the message will be sent out as a mail, cable, or telex operative credit instrument. Alternatively, the message may be rekeyed into a SWIFT format and sent out again as a SWIFT message. Some banks rely on SWIFT-compatible software to send the printout of the SWIFT message directly to the beneficiary without alteration and conversion into the receiving bank's paper-based format. This printout is also intended to function as the operative credit instrument.

The transition from a SWIFT to a nonSWIFT medium in this direct or unconverted method of transmission is not as trouble-free as it seems. Since the SWIFT message is not intended for use by beneficiaries, it may either contain directives that only banks need follow or lack clauses on which beneficiaries need to rely. As will be discussed shortly, these transitional problems have caused considerable uncertainty among bankers and banking lawyers.

6. Time of Establishment. In light of the speed with which SWIFT messages are communicated and the receiving bank's need to act quickly in response to the electronic request or instruction, the receiving bank must know as of what moment the sender of the message is irrevocably bound. Article 5 of the UCC refers to this event as "establishment" 50 and, almost uniquely, lays down specific rules by which it may be determined-a matter as to which even the UCP are silent. ${ }^{51}$

The establishment of the paperless letter of credit could occur at various times. The first time could be when the SWIFT message is released to the SWIFT access point, the second when the message is acknowledged by the receiving bank, and the third when the receiving bank performs the requested or instructed act. Other moments of establishment are conceivable, such as when the message actually reaches the recipient's "operations" computer (as distinguished from a mere "host" or "depository" computer), when the recipient's operations officers gain knowledge of the existence of the message, or when the message is received by the beneficiary. Yet none of these moments is sufficiently objectively ascertainable to warrant consideration.

49. Brickman interview (cited in note 26).

50. See UCC § 5-106 (West, 12th ed 1990).

51. See generally Kozolchyk, 9 Intl Encyclopedia Comparative L ch 5 at 104-10 (cited in note 5). 
Virtually every American and European banker interviewed by this writer pointed to the moment of release of the message as the moment when he deemed his liability established vis-à-vis correspondent banks. ${ }^{52}$ This moment usually coincides with the time the issuing bank records its liability and any other debits or credits related to the message in question. As a result both of regulatory requirements and of electronic programs that carry out the bank's issuance of credits and related bookkeeping functions, this recording (also known as "booking") occurs in conjunction with and immediately following release.

The bankers' choice of an ascertainable early moment of establishment performs an additional, nonbookkeeping function. It reassures the recipientcorrespondent bank that the advice, confirmation, negotiation, or payment of an irrevocable credit will not be revoked or canceled without its recipient's consent. Thus, if an issuer attempts to revoke or cancel its instruction or request after the receiving bank has complied with it, the receiving bank does not have to prove that it advised, confirmed, paid, or negotiated prior to the issuer's attempted revocation or cancellation. Proof of the advice, confirmation, negotiation, or payment will suffice to bind the issuing bank.

The SWIFT User Handbook does not state when a credit is established. Instead, these rules assure the issuer that messages not yet "delivered" to the intended recipient can be revoked or canceled.53 Let us assume, however, that issuer A sent a message requesting advising bank $B$ to forward to beneficiary $\mathrm{C}$ a "pre-advice" of a credit. In a subsequent phone conversation, A's employee indicated to bank $B$ that he had just sent the text of the operative credit instrument to SWIFT, that the terms and conditions of the

52. This information was obtained in response to a 1971 questionnaire sent to banks in several countries in connection with writing Kozolchyk, 9 Intl Encyclopedia Comparative L (cited in note 5). The questionnaire and replies thereto are filed in the libraries of the University of Arizona College of Law and the Max Planck Institute for Foreign and International Law in Hamburg. The questionnaire and related interviews have been updated for the fall 1992 projected publication by Little, Brown \& Company of Kozolchyk, On Letters of Credit. See also State of New York Law Revision Commission, 1 Hearings on the Uniform Commercial Code, Memoranda presented to the Commission and Stenographic Report of Public Hearing on Article 5 of the Code item 3 at 55 (reprint at 603) (1954 \& photo reprint 1980), especially written testimony before the committee by $\mathrm{Mr}$. John L. O'Halloran of Manufacturers Trust Co., stating that "once we have mailed that letter of credit, as far as I am personally concerned, the credit has been established." See also corroborating findings by Professor Schlesinger cited in Boris Kozolchyk, Is Present Letter of Credit Law Up to its Task?, 8 George Mason U L $\operatorname{Rev} 285,297-98 \mathrm{n} 19$ (1986), and the Court of Appeals for the Second Circuit findings on the irrevocability of CHIP's messages transferring funds once the message of transfer was released in Delbrueck v Manufacturers Hanover Trust Co., 609 F2d 1047, 1051 (2d Cir 1979). But compare UCC $\$ 4 \mathrm{~A}-211$ (a)-(c) \& comment 3. Article 10c of the proposed revision of article 10 of the UCP states in relevant part:

Unless the Nominated Bank is the Confirming Bank, nomination by the Issuing Bank does not constitute any undertaking by the Nominated Bank to pay, to accept, or to negotiate. Except where expressly agreed to by the Nominated Bank and so communicated to the Beneficiary, the Nominated Bank's receipt and/or examination and/or forwarding of the documents does not make that bank liable to pay, to accept, or to negotiate. See ICC Doc 470-37/4 (June 10, 1991).

53. SWIFT Rule 22.4.2.5 states: "The sender has the ability to cancel a message before the first delivery attempt is made. The system will abort a message after eleven unsuccessful delivery attempts and will inform the sender." 
message were exactly those of the pre-advice message, and that B should advise the irrevocable credit to the beneficiary immediately. Yet after A released its message of issuance to SWIFT but before the message reached $B$, A asked SWIFT to revoke or cancel the message of issuance, and SWIFT revoked or canceled it. This revocation or cancellation occurred after that moment when bankers feel they are irrevocably bound not only by their message of issuance, but also with respect to a pre-advised credit. And the consensus among banks and banking lawyers-now expressed in the proposed revision of the UCP-is that a pre-advice irrevocably binds the issuing bank to issue the operative credit instrument "without delay." 54

\section{SWIFT: Medium or Transactional Rules? The contrast between SWIFT} rules and the banking practices on revocability or cancellation of letter-ofcredit messages helps to identify SWIFT's type of rules. As is the case with UNCID, many of the SWIFT rules are what was referred to earlier as "medium" rules and also to what Professors Goode and Bergsten refer to as "system" rules. ${ }^{55}$ In this writer's opinion, system rules are a species in the genus of medium rules. Like other medium rules, system rules are designed

54. Subsection " $a$ " of article 11 of the proposed revision of the UCP reads, in pertinent part, as follows:

i. When an Issuing Bank instructs an Advising Bank by any authenticated teletransmission to advise a Credit or an amendment to a Credit, the teletransmission will be deemed to be the operative Credit instrument or the operative amendment, and no mail confirmation should be sent. Should a mail confirmation nevertheless be sent, it will have no effect and the Advising Bank will have no obligation to check such mail confirmation against the operative Credit instrument or the operative amendment received by teletransmission.

ii. If the teletransmission states "full details to follow" (or words of similar effect) or states that the mail confirmation is to be the operative Credit instrument or the operative amendment, then the teletransmission will not be deemed to be the operative Credit instrument or operative amendment. The Issuing Bank must forward the operative Credit instrument or the operative amendment to such Advising Bank without delay.

c. A preliminary advice of the issuance or amendment of a Credit (pre-advice) shall only be given by an Issuing Bank if such bank is prepared to issue the operative Credit instrument or amendment thereto. An Issuing Bank having given such pre-advice shall be irrevocably committed to issue or amend the Credit without delay.

ICC Commission on Banking Technique and Practice, Working Party Report-UCP 400 Revision 19, ICC Doc 470-37/4 (1991).

55. Bergsten and Goode insightfully distinguish between system and transaction rules, but also point out that whether such rules impose legal responsibilities on transmitters, recipients, and the system itself depends upon their purpose and interpretation. Some system rules exclude liability of the system for breakdown or malfunction, while others are silent on the question of responsibility. Bergsten and Goode conclude that:

While system rules are not directly concerned with the underlying trade transaction, they have an indirect effect, in that a communication transmitted through the system may prove legally ineffective in achieving its contractual purpose if the sender fails to conform to the system rules. Conversely, successful transmission through the system will normally result in contractually effective communication. The potential existence of a link between systems rules and transaction rules is clearly brought out in that part of the SWIFT Handbook dealing with the electronic transmission of documentary credits. "A documentary credit advised to the beneficiary or another advising bank based on a Swift message constitutes an operative credit instrument unless otherwise specified."

Eric Bergsten \& Roy M. Goode, in Hans B. Thomsen \& Bernard S. Wheble, eds, Trading with EDI ch 7 at 125,134 (1989). 
to instill diligence in the effective use of the electronic medium. Unlike medium rules, however, which apply to an open-ended number of users, system rules apply only to the participants in a given system or network of telecommunications. Finally, and most importantly, unlike transactional rules, medium and system rules should not confer rights or impose duties with respect to the underlying "messaged" transaction. The SWIFT rule that allows revocation or cancellation prior to delivery of the message confuses its mission. It is not supposed to confer a power of revocation or cancellation of the underlying message; only the UCP or applicable statutory, decisional, or administrative law can confer such a power. SWIFT's rule, therefore, should be solely to inform users that if applicable law allows revocation or cancellation, SWIFT has the capability of effecting such up to a certain moment.

\section{Rules on Liability.}

a. Negligence and fraud. The risk of a negligent or fraudulent transmission is shared by SWIFT and its users. SWIFT's own liability for negligence and fraud is guided by one major principle and several corollaries. The major principle is that SWIFT is not liable for any segment of the teletransmission not directly under its control. ${ }^{56}$ Thus SWIFT is responsible for the maintenance of security in the part of the system that it controls-that is, the regional processors, operating centers, communication facilities, and transmission lines between and among the regional processors and the operating centers. ${ }^{57}$ SWIFT is not responsible, however, for the security of the communications facilities and transmission lines between and among the regional processors and the users' computer terminal facilities or for the security of the users' premises and terminal facilities. Security within these premises and facilities is the responsibility of the users. ${ }^{58}$

Corollaries of the area-of-control principle are:

56. See SWIFT Rule 21.5.1, which states:

SWIFT is responsible for the complete international network. Looking at it from the user's point of view, this means that SWIFT is responsible for the message from the time it reaches SWIFT owned equipment (generally the digital port on the regional processor) to the time it leaves SWIFT owned equipment .... In the part of the system controlled by SWIFT, SWIFT is responsible for the maintenance of security as decided by the Board of Directors and detailed in the Policy Volume. This part of the System is limited to the regional processor's (including the gateway), Slice Processors and System Control Centers, communication facilities and transmission lines between the regional processor's, the Slice Processors and the System Control Processor.

57. Id.

58. See, among others, SWIFT Rule 21.5.1 (last paragraph) which states:

SWIFT does not accept responsibility for the security of any communication facilities and transmission lines between the regional processor's and the users' terminal facilities, or for the security relating to the user's premises or terminal facilities or the use thereof.

See also Rule 22.1.2.1, which states:

Once an LT (logical terminal) has been authorized for access to the SWIFT system, it is the user who is responsible for control of its use. This control includes allocation of input sequence numbers and the checking of output sequence numbers. It also includes keeping the log-in and select sequences secure for every logical terminal, and using them correctly. 
(1) SWIFT is not responsible for loss or damage caused by a technical failure or force majeure;59

(2) SWIFT is not responsible for an unauthorized transmission unless the victim proves that SWIFT could not reasonably have assumed the validity of the transmission; 60

(3) SWIFT is empowered to use any reputable third party with regard to the transmission of messages; 61

(4) SWIFT is not responsible for unauthenticated payments or transfers, whatever the category or type of message, or for the negligence of a user or lack of cooperation between users, or for the users' failure to follow Handbook procedures when such failure is "an essential element in the events leading to the loss or damage incurred;"'62

(5) SWIFT is liable for its negligent acts, errors, or omissions in failing both to perform the services and to maintain the security procedures described in the Handbook; 63 and

(6) SWIFT is liable for fraud by its employees, subcontractors, and third parties when acting within the area under SWIFT control.

In the case of third-party fraud, SWIFT bears responsibility only if it could not have reasonably assumed the validity of the message ${ }^{64}$ or if the fraud was made possible by SWIFT's failure to follow the security procedures outlined in SWIFT's Handbook.

If SWIFT's negligence or the fraud of its employees, subcontractors, or third parties acting within SWIFT's area of control is established, SWIFT is liable only for the users' "direct" losses or damages. ${ }^{65}$ Direct losses are defined as: (1) "a non recoverable loss of funds representing the principal amount of authenticated payments or transfers, whatever the category or type of message sent through the SWIFT system and (2) a loss of interest arising from a loss in (a) above ...."66 SWIFT users are required to "take all action necessary to keep interest expenses to a minimum, that is, shall take into

59. SWIFT Rule 23.1 states:

The Company shall not be responsible for any loss or damage caused by a failure to carry out, or delay of messages resulting from a technical failure, unless otherwise provided in the User Handbook, or force majeure. Force majeure shall include acts of authorities including PTT authorities, strike or industrial dispute, political disturbance, catastrophes in nature, fire, war, epidemics and all other circumstances which prevent the Company against its will from carrying out its activities. Moreover, the Company shall not be responsible for any loss or damage caused by the performance of non-authorized transmission orders unless the prejudiced party proves that the company could not reasonably assume the validity of those orders. The Company shall be entitled to make use of any reputable third party with regard to the transmission of messages, at the risk of the ordering user.

60. Id.

61. Id.

62. SWIFT Rule 23.4.2.

63. Id.

64. SWIFT Rule 23.4.2(c), (d).

65. SWIFT Rule 23.4.2.

66. SWIFT Rule 23.4.1. 
account any undue enrichment."67 SWIFT limits its liability for direct losses through fraudulent or dishonest acts by its employees to the sum of three billion Belgian francs (approximately 1.3 billion dollars) for any one loss or series of losses arising out of the same event and to six billion Belgian francs (approximately 2.6 billion dollars) in the aggregate for each annual period. ${ }^{68}$ A similar limitation applies to liability for errors and omissions and fraud. If the claims for the above categories exceed the amount available in SWIFT's annual maximum aggregate liability fund, then the annual maximum indemnity available will be apportioned among the claimants on the basis of the amount of messages involved during the year. ${ }^{69}$ The above limitation is accompanied by a two million Belgian franc deductible per claim. ${ }^{70}$

b. Delay and loss of interest. Disputes on the loss of interest on funds not timely received are common among SWIFT's users. At times, the claim is caused by a delay in the issuance of the transfer message or in the relay of an instruction to transfer funds. At other times, the claim is caused by a recipient's failure to make available the funds transferred in timely fashion. ${ }^{71}$ In 1979, SWIFT enacted rules that allocated liability for such interest losses. ${ }^{72}$ These rules address the issue of choice of law as well as such substantive law issues as standard of care and amount of recovery. Belgian law is said to be applicable to "all relations, including the rights and obligations between SWIFT and the users."73 The SWIFT rules also set forth guideposts for the "time of receipt" of the message, ${ }^{74}$ "value date,"75 and "cut-off time,"76 without which it would be very difficult to allocate liability for loss of interest because neither the beginning nor the end of the delinquent period could be established with certainty. ${ }^{77}$ In claims of loss of interest, the deductible is

67. Id.

68. SWIFT Rule 23.4.3.

69. Id.

70. Id.

71. See Swift Board Paper 185, Responsibility and Liability § 2(b) (April 1979) (cited in Note, 13 Cornell L. Rev at $315 \mathrm{n} 29,320-25 \mathrm{nn} 69-101$ (cited in note 29).

72. SWIFT Rule 22.4 (late payments).

73. SWIFT Rule 23.2.

74. SWIFT Rule 22.4.2.1 states that " $[t]$ he time of receipt of a message at the receiving terminal shall be the output time as recorded by the regional processor in the application output header. This is also the time of receipt for cut-off time purposes."

75. According to Rule 22.4.2.2, "[t]he value date defines the date when the amount of the transfer is at the disposal of the Receiving User. In SWIFT, the value date is indicated, e.g., in Field $32 \ldots .$.

76. SWIFT Rule 22.4.2.3 states that "[c]ut-off time is the latest time of day (by country/time zone) for Receiving Users to apply same day value to effect funds transfers in domestic currency in favor of third parties. Cut-off time for a destination is the cut-off time shown in the Address/Geographical section of the Swift Directory for location of the destination."

77. Since the late payment could be the responsibility of either SWIFT or of the sender or receiver of the SWIFT message (SWIFT Rule 22.4.1), a standard of care had to be established for each of these participants. SWIFT was made responsible if (1) the message that it acknowledged to the sender did not appear on the "Undelivered Message Report" and was not delivered; (2) SWIFT failed to notify a user promptly of a failure on the part of SWIFT personnel; and (3) SWIFT failed to notify a user promptly of a failure of the SWIFT network. SWIFT Rule 22.4.3. A sender was made responsible by the SWIFT rules if (1) the message was not acknowledged by SWIFT, and the sender 
100,000 Belgian francs (approximately $\$ 30,000$ ) per event of loss or damage. If the aggregate of loss of interest claims exceeds fifty million Belgian francs, the reimbursement is on a prorated basis. ${ }^{78}$

c. The model for SWIFT liability rules. There is a striking similarity between the SWIFT rules on liability and the liability rules developed by U.S. statutory and treaty law at the turn of the twentieth century for losses resulting from maritime carriage. ${ }^{79}$ Echoing the Harter Act and the Hague Rules, ${ }^{80}$ the SWIFT rules allocate liability among the carrier (SWIFT), the users of the service (sending and receiving banks), and their respective insurers as if all the parties were joint venturers in a carriage-of-messages enterprise. Certain risks are borne jointly, others severally. Liability is allocated once the physical and legal boundaries of responsibility are laid down. The principle that underlies allocation of liability is that SWIFT, as the carrier, must be shielded against losses likely to cripple the carriage enterprise. This principle may not qualify as the "cheapest cost avoider" for believers in the dogma of economic efficiency, ${ }^{81}$ but judging from the mushrooming number of SWIFT users and from the continuing low cost of the service, it has worked well. Moreover, neither SWIFT nor CHIPS rules require their systems to assume liability for all losses of principal resulting from system failure. ${ }^{82}$ SWIFT, as indicated earlier, does, however, assume

did not initiate an adequate "reconciliation procedure" to insure receipt of all acknowledgments; (2) the message was acknowledged by SWIFT and then appeared in the Undelivered Message Report; (3) SWIFT had not responded prior to the cut-off time at the receiving location to the specific delivery monitoring instructions requested by the sender; (4) a transaction requiring a SWIFT format was sent in another format; (5) the sender did not react promptly to SWIFT's notification that a user, regional processor, or system control center had failed to operate or had a faulty operation; and (6) the message contained an invalid or wrong address in the header or text. SWIFT Rule 22.4.4. The receiver was deemed responsible if it (1) did not process by giving appropriate value to messages validly addressed and received prior to cut-off time; (2) did not react promptly to SWIFT notifications concerning operational use of the system; (3) failed to perform an adequate reconciliation to insure receipt of all messages from SWIFT; (4) failed to adhere to the Handbook's computer Terminal Policy rules or failed to notify SWIFT 24 hours in advance of its inability to adhere to the Terminal Policy; and (5) failed to follow normal banking practice and did not inquire as soon as possible about messages that did not comply with the SWIFT standards, did not authenticate correctly, or contained an address not listed in the SWIFT directory and consequently could not be processed in the usual manner. SWIFT Rule 22.4.5.

78. SWIFT Rule 23.5.2.

79. See generally Boris Kozolchyk, Evolution and Present State of the Ocean Bill of Lading from a Banking Law Perspective, 23 J Maritime L \& Commerce 161 (April 1992).

80. The Harter Act, 27 Stat 445 (1893), codified as amended at 46 USC $\$ \S 190-96$, and the Hague Rules, Convention Internationale Pour L'Unification de Certains Règles en Matière de Connaissement Signée à Bruxelles, Le 25 Août 1924, U.S. Treaty Series No 931, 51 Stat 233 (official text is French).

81. See, for example, Lingl's evaluation of the cheapest cost avoiding liability rules in SWIFT and CHIPS rules, as inspired by Guido Calabresi and Ronald Coase. Lingl, 22 Harv Intl $\mathrm{L} \mathrm{J}$ at 63052 (cited in note 8), quoting Guido Calabresi, The Costs of Accidents: A Legal and Economic Analysis (Yale U Press, 1972) and Ronald H. Coase, The Problem of Social Cost, 3 J L \& Econ 1 (1960).

82. Rule 15 of the New York Clearing House Association provides that " $[t]$ he Clearing House shall not be responsible for any loss in the use of funds resulting from a system error." See Rules Governing the Clearing House Interbank Payment System (NYCHA, 1981), citing Lingl, 22 Harv Intl L J at 635 (cited in note 8). Similarly, SWIFT Rule 23.1 states that "[t]he Company shall not be 
liability for interest losses caused by a system or personnel failure. ${ }^{83}$ In addition, the SWIFT rules provide an informal arbitration procedure to handle user claims for recovery of losses or damages rejected by SWIFT. ${ }^{84}$

The SWIFT rules do not cover the risk created by fluctuating exchange rates between the time a transfer of funds is initiated and the actual time the transfer is effected. Some commentators find this a significant coverage gap. ${ }^{85}$ In the absence of a SWIFT rule on the fluctuating exchange risk, under U.S. law, this risk is likely to continue to be borne by the applicant. ${ }^{86}$

\section{B. The SWIFT User Handbook as a Source of Electronic Letter-of-Credit Law}

If a SWIFT letter of credit were to become the subject of litigation, it is unclear how the court would characterize and rank the SWIFT rules. The SWIFT User Handbook may be characterized as carrier-promulgated rules that are binding on only those users of the system who expressly agree to be bound by them. Alternatively, the SWIFT User Handbook may be regarded as sufficiently reflecting widespread banking practice to bind all the parties who participate, directly or indirectly, in the electronic letter-of-credit transaction, regardless of their expression of consent. And even if the latter were to become the prevailing characterization, it is still unclear how the SWIFT User Handbook would rank with respect to the UCP, especially when the latter cover some of the same issues.

A LEXIS search found no decisional law applying SWIFT rules to SWIFTissued letters of credit. ${ }^{87}$ The search then turned to decisions dealing with rules or guidelines promulgated by other systems of interbank communication. One such decision disclosed is Delbrueck v. Manufacturers Hanover, ${ }^{88}$ which involved the binding effect of CHIPS. The Delbrueck court held that "the practices associated with banking transactions can be

responsible for any loss or damaged caused by failure to carry out, or delay of, message resulting from technical failure...."

83. SWIFT Rule 22.4.3.

84. SWIFT Rule 23.3.

85. See Note, 13 Cornell Intl L. J at 325-27 (cited in note 29).

86. See Richard v American Union Bank, 241 NY 163, 168, 149 NE 338, 339 (1925).

87. A LEXIS search of the term SWIFT in U.S. federal and state law libraries produced only one federal court decision. Lloyds Bank v Lynch, 702 F Supp 157 (ND Ohio, 1988). A similar search in European LEXIS libraries failed to produce any decision. The libraries searched were: Enggen (for English decisions), Prive (for French decisions, including Biblio (tous fichiers reunis)), Appel (Cours d'Appel, July 1983 to Sept 30, 1987), from Oct 1980, Cassci (Cours de Cassation, Chambres autre que Criminelle, Oct 1959 to March 13, 1991), and Eurcom (for European Community cases from November 1954 to December 1990). No references to SWIFT were found in German commentaries such as Baumbach, Duden, Hopt, Handelsgesetzbuch, 26 Auflage 1985 and commercial law reporters such as Wertpapier-Mitteilungen, or in Italian reporters such as Foro Italiano or journals such as Banca, Borsa e Titoli di Credito. Argentina, with Latin America's best decisional law reporting system, has no entries in the alphabetical index of reporters such as La Ley and Jurisprudencia Argentina. A similar void was apparent in Spain's Repertorio de Jurisprudencia Aranzadi.

88. 609 F2d 1047 (2d Cir 1979). 
conclusive evidence of the legal effect of those transactions." 89 Hence, CHIPS rules were given the binding effect accorded to standard banking practices. ${ }^{90}$

Delbrueck addresses one of the most important features of electronic assumption of liability by a bank communicating with another bank. The plaintiff, a German banking partnership, agreed with Herstatt, a large German bank, to exchange German marks for U.S. dollars in three separate remittances of dollars to Herstatt's account with Chase Manhattan Bank ("Chase") in New York. Two remittances were due on June 26, 1974, 2.5 million dollars and 10 million dollars, respectively. Another remittance for 10 million dollars was due on June 27, 1974. In accordance with the authorization procedure, Delbrueck sent a telex message to the defendant on June 25, 1974, ordering the transfer, on June 26, of a total of 12.5 million dollars to Chase for the account of Herstatt. Early in the morning of June 26, Delbrueck authorized the payment of the $\mathbf{1 0}$ million dollars due on June 27. Herstatt was closed by the German banking authorities around 10:30 a.m. on June 26. Chase became aware of the closing and froze payments out of Herstatt's account but continued to accept transfers. Delbrueck sent a telex message to Manufacturers Hanover Bank at 11:30 a.m. on June 26, requesting that the 10 million dollars transfer scheduled for June 27 be stopped. A few minutes later, at 11:36 a.m. and 11:37 a.m., respectively, the defendant transferred to Chase via CHIPS the $\mathbf{1 0}$ million dollars and $\mathbf{2 . 5}$ million dollars ordered by the plaintiff on June 25 and due on the 26 th. The plaintiff called the defendant at around noon and later sent a telex message, trying to stop or recall the $\mathbf{1 2 . 5}$ million dollars in payments that had already been transferred to Chase. During that afternoon, both the defendant and the plaintiff made phone calls to Chase in an attempt to obtain the return of the funds. These calls were unsuccessful and at 9:00 p.m. of the evening of June 26, Chase formally credited Herstatt's account with the 12.5 million dollars. ${ }^{91}$

89. Id at 1051 .

90. Id.

91. Judge Broderick's description of the CHIPS process is quite instructive:

When the paying or sending bank (Manufacturers) receives a telex from one of its customers (Delbrueck) instructing it to make a payment to a receiving bank (Chase), another member of the CHIPS system, for the account of one of the receiving bank's customers (Herstatt), the paying bank (Manufacturers) first tests and verifies the telex. Thereafter, the tested and verified telex is sent to one of the CHIPS computer terminal operators and the payment order contained in the telex is programmed into the terminal by typing into the computer the relevant information-i.e., the identifying codes for the party originating the transfer (Delbrueck), the remitting bank (Manufacturers), the receiving bank (Chase), the party for whom the receiving bank is receiving the transfer (Herstatt) and the amount of the transfer ( $\$ 10$ million and $\$ 2.5$ million). This information is then transmitted to the central computer located at the Clearing House, which, based upon the identifying codes, searches out all the necessary clerical information, stores the message and causes a sending form to be automatically typed at the sending bank. In this case, this step was effected on June 25, 1974. Once the programming of the computer has been completed, the send form is sent to the appropriate area at the sending bank for approval. When a determination is made at the sending bank (Manufacturers) to make the payment, the form is returned to one of the computer terminal operators, re-inserted in the computer and the release key is depressed. At that moment, the central computer at the Clearing House causes a credit ticket to be 
The plaintiff argued that the transfers made by the defendant were revocable until 9:00 p.m. and that by failing to revoke the transfers, the defendant had negligently breached its implied creditor-depositor contract with Delbrueck. As characterized by the United States Court of Appeals for the Second Circuit, the crucial issue on the appeal was whether the transfers of funds via CHIPS at 11:36 a.m. and 11:37 a.m. were final.' The court held that the transfers were irrevocable and affirmed the dismissal of the complaint. By examining the CHIPS Manual, the court determined that CHIPS transfers were intended as replacements of interbank cashiers' checks, especially in large payments. ${ }^{92}$ And since it was undisputed that cashiers' checks were irrevocable when transferred to the payee bank, the court concluded that a similar rule should apply to CHIPS transfers. The court traced the short history of CHIPS revocation rules and established that prior to the Herstatt bankruptcy, there had obtained a rule of tacit irrevocability once the transfers were released, except for the correction of clerical errors. Albeit unwritten, this rule reflected the views of participating banks. The court also found that plaintiff's conduct reflected recognition of the same rules in that it initially requested the stop payment only on the 10 million dollars to be paid on June 27, "apparently believing that the June 26 transfers had been made and were irrevocable." 93 The Herstatt failure caused the enactment of a new rule to help reduce the backlog of releasing orders owing to the reluctance of transferor banks to release payment orders until they were certain that funds were available to cover them. By allowing revocation up until the moment of crediting the account of the payee, transferor banks were encouraged to release the mounting number of payment orders. The new procedure allowed member banks to release payments but gave them the right to recall these payments until 10:00 a.m. the morning after the transfer. As pointed out by the court, this change would not have been required if the transfers were considered revocable by member banks. Consistent with the practice of issuing irrevocable transfers, CHIPS reverted a few months later,

printed automatically at the terminal of the receiving bank (Chase) and a debit ticket to be printed at the terminal of the sending bank (Manufacturers). Further, the central computer automatically makes a permanent record of the transaction and debits the Clearing House account of the sending bank and credits the Clearing House account of the receiving bank. In this case, this step was effected at $11: 36$ and $11: 37$ for the $\$ 10$ million and $\$ 2.5$ million payment, respectively, from Manufacturers for Delbrueck to Chase for Herstatt.

The funds received by a receiving bank (e.g., Chase) for the account of one of its customers (e.g., Herstatt) via the receipt of a CHIPS credit message are made available to the customer and can be drawn upon by the customer in the discharge of its obligations that same day, as soon as the receiving bank is aware of the fact that the funds have been received. This running tabulation by the receiving bank is generally referred to as a "shadow balance."

At the end of the day, the central computer correlates all of the day's transactions, nets out the debits and credits and prints out reports showing which banks owe money and which have money due them. That information is delivered to the New York Federal Reserve Bank the next business day and adjustments are made on the appropriate books of account.

Delbrueck Co. v. Manufacturers Hanover Trust Co. , 464 F Supp 989, 922 n5 (SD NY 1979).

92. “' CHIPS completely eliminates checks for interbank payment transfers' (App 377).” 609

F2d at 1050 (citing the CHIPS manual).

93. Id. 
once the backlog problem was resolved, to the initial, tacitly accepted rule of irrevocability and finality of transfers when they were released.

The Delbrueck decision is significant because it (1) aligns the CHIPS presumption of irrevocability with that of paper-based and paperless credit customs; (2) holds that CHIPS practices are conclusive evidence of the legal effect of CHIPS transfers; and (3) applies CHIPS rules to the plaintiff, a nonCHIPS member. The court may have relied on the assumption that the plaintiff, in attempting to stop payment of only the June 27 transfer, evinced familiarity with CHIPS rules and thus consented to them. ${ }^{94}$ Alternatively, the court may have assumed that a banking practice, once set forth in written form by the association involved, automatically applies to parties such as the plaintiff, regardless of express consent. Either of these views contrasts markedly with those of European courts. Commenting on the attitude of French courts, Christian Gavalda and Jean Stoufflet state that those courts evidence "considerable prudence when accepting the presence of trade usage, especially when invoked by a bank against a client" ("Les tribunaux témoignent d'une assez prudence pour admettre l'existence d'un usage, surtout lorsque cet usage est opposé par une banque à un client.")..$^{95}$ Thus, according to these writers, a usage will not be deemed to exist "unless it is a practice known to all and is uncontested" ("une pratique est connue de tous et n'est plus contestée"), ${ }^{96}$ although the "consecration of trade usage" may come about by a judicial decision. ${ }^{97}$ Similarly, German commentators point out the need for objective as well as subjective elements in the enforcement of trade usage. Among the objective elements are the "proof of actual practice" ("Tatsäachliche Übung"), including its regularity, consistency, and noncoerciveness over a certain period of time. ${ }^{98}$ In addition, as a subjective element, German courts require proof of the parties' awareness of the particular usage.99 Given the unhesitating application of the CHIPS Manual to a nonCHIPS member by a court as commercially important as the United States Court of Appeals for the Second Circuit, it is necessary to explore further the interaction between the SWIFT rules and such rules of broader application as those found in the UCP and UCC.

\section{Application of the UCP to SWIFT Credits}

1. The Transition to the "Hard Copy" Problem. SWIFT terminology, message standards, and location and spacing of data fields in letter-of-credit messages are all inspired by UCP principles and rules. ${ }^{100}$ This dependency explains the

94. Id.

95. I Droit de Credit 51 (Les Institutions, 1990).

96. Id, citing Paris, 6 Dec 1933: Gaz Pal 1934, 1, 122.

97. Id, citing Com 20 déc 1954, D 1955, J, 83; Trib Com Nice 3 Nov 1965.

98. See Volker Emmerich, et al, 4 Handelsgesetzbuch app $\$ \S 343-460$ (1990) (comment by Horn).

99. Id.

100. As stated in chapter 1 of SWIFT's Handbook: "Applying these principles of the ICC UCP, the rules and basic text of these message types are given in English ...." Swift User Handbook ch 1 at $1-1$. 
generic, albeit tacit, incorporation of the UCP into SWIFT credits. SWIFT's Category 7 first operational guideline is: "Unless otherwise specified, the Documentary Credit is issued subject to the Uniform Customs and Practice for Documentary Credits." 101 Uncertainty as to the application of the UCP to SWIFT credits arises, however, once a SWIFT credit is printed and delivered to a beneficiary. It must be asked whether such a "hard copy" (letter, cable, or telex) of the SWIFT-transmitted letter of credit is the operative credit instrument where the beneficiary is concerned. If it is the operative credit instrument, is it subject to the UCP, SWIFT, or a combination of them? These questions are significant because the hard copy is a literal version of the SWIFT message, and this message, as indicated earlier, does not expressly incorporate the UCP. Yet the UCP require that they be expressly incorporated in the operative credit instrument by providing that the UCP "shall be incorporated into each documentary credit by wording in the credit indicating that such credit is issued subject to the [UCP], 1983 revision, ICC Publication No. 400."102

Some issuing banks use software that warns advising banks to state in its advice to beneficiaries that the credits are subject to the UCP. Other issuing banks, however, insist that the express incorporation of the UCP requires mention of such an incorporation in any teletransmission by their correspondent banks. These conflicting practices have generated disputes among banks and banking associations, both of which have asked the ICC Banking Commission for an advisory opinion. ${ }^{103}$ Although the Commission has not provided such an opinion, it has acknowledged that a problem arises once the message is sent to a beneficiary or to another party outside the SWIFT network. ${ }^{104}$ The Commission has also acknowledged that in some regions, such as the Middle East, banks deem it essential to mention the UCP in every letter-of-credit text. ${ }^{105}$ For this reason, the Commission has recommended that a short code be included in the SWIFT message type to print out the UCP incorporation clause. ${ }^{106}$

Notwithstanding the Banking Commission's recommendation, the problem has persisted, and the Israeli National Committee has suggested that in the event the suggested code was not inserted, issuing banks include language of incorporation on a given data field. ${ }^{107}$ In response to the Israeli suggestion, the Commission was more categorical, and despite expressing a "personal preference" for a reference to the UCP printed out in the SWIFT format, it confirmed that the ICC had already ratified the exclusion of such a

101. Id ch 4 at $4-1$ (Scope).

102. See 1983 UCP art 1.

103. See Meeting of May 28, 1986, ICC Docs 470/479, 470/481 (1986); Opinion R101 at 21, ICC Docs 470/479 (1984-1986).

104. Id.

105. Id.

106. Id.

107. See ICC Docs 470/538, 470/561 (1988). 
statement. ${ }^{108}$ In addition, the Commission believed that the problem raised by the Israeli Committee "was not a UCP question as such, but rather a SWIFT software problem."109 The Commission referred the Israeli Committee to a report submitted by the representative of the British Bankers Association, which called attention to the fact that "if a documentary credit message was then used outside the SWIFT environment, SWIFT would have no control over its use and a specific reference to the UCP would have to be included in the onward transmission." 110

The issue of the express incorporation of the UCP in SWIFT messages is of more than ritualistic interest. Contrary to SWIFT's apparent perception, " " the decision to exclude the "extra words" concerns more than economy of space.

\section{SWIFT v. UCP: Medium or Message?}

a. Negotiation and the enabling clause. The SWIFT message that appears printed in the hard copy produced by the receiving bank's computer transcribes SWIFT directives to the advising or confirming banks. One of these directives is found in SWIFT's data field 41 (a) option (d), which states, "If the credit is to be freely negotiable by any bank, option D must be used with the phrase "Any bank in . . (city or country)," and, "[i]f the credit is to be freely negotiable by any bank anywhere in the world, an indication of country is not required." 112 The language in this directive falls considerably short of that in the so-called "enabling" clause still inserted in many of the paper-based, freely negotiable credits: "We hereby engage with the drawers, endorsers and bona fide holders of drafts drawn under and in compliance with the terms of the credit that such drafts will be duly honored upon presentation." 113

More than a ritualistic phrase, this enabling clause empowers negotiation of drafts drawn under "freely negotiable credits." Without it or some equivalent authorization, letters of credit are restricted in their negotiation

108. Id.

109. Id.

110. Id.

111. See Opinion R151 at 13, 14, ICC Doc 469 (1987-1988), which quotes Terry J. Mitchell of the British Bankers Association Representative to the ICC Banking Commission as stating that

[a] though he would personally have preferred that SWIFT foresee a clause specifically stipulating that the credit was subject to the UCP rather than leaving a default situation, nevertheless the SWIFT view is that the current situation has already been agreed by the ICC and so unless otherwise stipulated the credit will be subject to the UCP. Of course, problems could arise when the credit falls outside of SWIFT system and the banks have to annotate a credit to be in accordance with UCP.

112. See SWIFT User Handbook ch 24 at 24-6, field 41a, Message Type 720/721, Release 90/2 (May 1991).

113. See, for example, the format of an irrevocable negotiation credit in Boris Kozolchyk, Commercial Letters of Credit in the Americas app 2 at 694 (Matthew Bender, 1966). Unfortunately, the letter-of-credit forms included in ICC Pub No 416 do not include the customary enabling clause language transcribed in the principal text, thereby adding to the uncertainty of the power to negotiate. 
and must be treated as "straight" or "specially advised."114 Not surprisingly, then, banks have objected to the absence of an enabling clause in the transcription of the SWIFT message used as an operative credit instrument. In one such instance, an advisory opinion was requested from the ICC Banking Commission"15 by Dresdner Bank A. G. Hamburg ("Dresdner Bank"), which complained about credits issued by "Commonwealth countries" that transcribed the SWIFT message and failed to include the enabling clause. In these credits, the type of the commercial letter of credit was to be inferred from the instructions given in field 41 (a)-(d), as quoted above, and from the authorization given to the receiving bank to reimburse itself by debiting the account of the issuing bank in its books. According to this bank:116

Now it happens, once and again that the beneficiary of such a documentary credit message insists on having it handed over to him. Often, an amendment or an extension will follow at a later date, which is no doubt to be handed over as well. It is now up to the beneficiary to present this operative credit instrument together with subsequent messages concerning amendments or extensions, if any, and with the documents against which it is available to any bank of his choice for negotiation.

Although not fully spelled out by Dresdner Bank, the danger of the objected practice is the uncertainty it creates with respect to negotiation. Does the purported operative credit instrument truly enable any bona fide holder of the draft to demand honor of the credit despite the absence of the traditional or equivalent enabling clause? And assuming that the answer is affirmative, what then constitutes the operative credit instrument as far as the bona fide holder is concerned? Is it the original SWIFT unamended text as presented by the beneficiary to the negotiating bank, or is it the text modified by all the amendments accepted by the beneficiary either expressly or

114. Kozolchyk, 9 Intl Encyclopedia Comparative $\mathrm{L}$ at 34,35 (cited in note 5). Article $11 \mathrm{~b}$ of the UCP states, in relevant part:

(b) All credits must nominate the bank (nominated bank) which is authorized to pay (paying bank), or to accept drafts (accepting bank), or to negotiate (negotiating bank), unless the credit allows negotiation by any bank (negotiating bank).

$\cdots$

(d) By nominating a bank other than itself, or by allowing for negotiation by any bank, or by authorizing or requesting a bank to add its confirmation, the issuing bank authorizes such bank to pay, accept or negotiate, as the case may be, against documents which appear on their face to be in accordance with the terms and conditions of the credit, and undertakes to reimburse such bank in accordance with the provisions of these articles.

It could be argued that SWIFT's directive language "any bank in" is as effective an enabling clause as the traditional one. Yet, different meanings are ascribed to "negotiation," not only in different countries but also by banks and banking lawyers. Many banks believe that to "negotiate" a credit means to take up documents for examination and possible future payment whereas lawyers understand by negotiation to give value for a negotiable instrument, such as a draft. In light of the ambiguity surrounding negotiation, and the absence of a reference to drafts or other negotiable instruments in the SWIFT directive, it does not, in this writer's opinion, qualify as a fully fledged negotiation enabling clause.

115. See Meeting of April 23, 1985, ICC Docs 470/444, 470/450, 470/452 (1985); Opinion R100 at 19, 20, ICC Doc 434 (1984-86) ("R 100").

116. R100 at $19 \& 20$ (cited in note 115 ). 
tacitly? 117 While the latter uncertainty also arises with respect to amendments of nonSWIFT transcriptions, the uncertainty in the use of the SWIFT transcription is more serious. Consider, for example, the effect of amendments that arrive after the receiving bank gives or sends out its transcription of the SWIFT message to the beneficiary but before the time it would have taken it to prepare its own nonSWIFT software version of the credit.

Dresdner Bank argued that the SWIFT message is not suited to act as an operative credit instrument because it was only conceived of as a bank-to-bank message and did not even bear a signature. ${ }^{118}$ It maintained that to use such a message in communications with the beneficiary creates flaws in the security of the transaction, especially for the negotiating bank. Finally, Dresdner Bank pointed out that it is doubtful whether the SWIFT transcription binds the sending bank to the beneficiary —or put differently, whether the transcription is the operative credit instrument. ${ }^{119}$ Regrettably, the Banking Commission sidestepped the issues of the transcription's insufficient authorization for negotiation and its inability to serve as the operative credit instrument. ${ }^{120}$ These issues highlight the inability of SWIFT's message to serve as the operative credit instrument as far as the beneficiary is concerned.

b. Conflicting procedures and definitions. SWIFT procedures are significantly at odds with procedures set forth for the very same transactions by the UCP. Consider, for example, the negotiation procedures in both sources. The SWIFT User Handbook requires that "the advice to the beneficiary must be presented at each negotiation," and "[ $t]$ he negotiation bank must note each negotiation on that advice." 121 In contrast, the UCP requires neither the presentation of the advice at each negotiation nor a notation for each negotiation. ${ }^{122}$ This conflict raises a number of

117. The beneficiary's tacit acceptance of an amendment by tendering documents in compliance with that amendment is recognized by a widespread banking practice established by this writer in the process of establishing the customs of banks in the United States in connection with the revision of the UCP. Often, however, banks require the beneficiary's express consent when the amendment accepted by the tendered document may affect other terms of the credit, for example, a reduction of the amounts and change in the shipment dates.

118. As a rule, the receiving bank that sends out a literal transcription of the SWIFT message states in the letter accompanying the transcription that the attached message was received via SWIFT. See R100 at $19 \& 20$ (cited in note 115 ).

119. Id at 20 .

120. In id, the ICC Banking Commission merely dismissed the security concerns, as also present with telex and cable messages and restated the principle of generic and silent incorporation of the UCP in the SWIFT transcription. In a phone interview on August 1, 1991, Charles del Busto, Chairman of the Banking Commission, indicated that certain beneficiaries complained about the practice of sending the SWIFT printout as the operative credit instrument despite the fact that it was not a communication by the issuer to them. This procedure left unclear the duties of the advising bank in releasing this instrument. Some of these beneficiaries requested transmittals in the form of direct communication via safety paper. These complaints were heard when Message Type 700 was used for the first time.

121. SWIFT User Handbook ch 4 at 4.1 , II 1 \& 2, Message Type 700/701.

122. See 1983 UCP article 10b.4 which states: "If the credit provides for negotiation-to negotiate without recourse to drawers and/or bona fide holders, draft(s) drawn by the beneficiary, at 
troublesome everyday practice questions, such as: (1) Can a confirmingnegotiating bank that negotiates a credit subject to the UCP reject a tender of documents that does not contain a hard copy of the credit advice even if such a requirement is not listed among the terms and conditions of the operative credit instrument? (2) Can a bank that has issued a credit subject to the UCP and silent on the need to present the operative credit instrument refuse to reimburse a confirming bank that did not require such an instrument and/or failed to notate the negotiation? (3) Is an issuing bank bound to honor such a presentation if the beneficiary bypasses the confirming bank and presents the documents directly to it?

If either the confirming-negotiating bank or the issuing bank can reject the beneficiary's tender of documents based on the SWIFT User Handbook, then these rules have trespassed upon UCP territory. Unpaid beneficiaries would be justified in claiming detrimental reliance on the terms of the credit, the UCP, or UCP-inspired practices. Similarly, legitimate complaints would be heard with respect to SWIFT's definition of the operative credit instrument. In accordance with the SWIFT User Handbook, "[u]nless otherwise specified, a Documentary credit advised to the Beneficiary or another Advising Bank based on a SWIFT message constitutes an operative credit instrument."123 In contrast, the UCP require that if the teletransmission is to be the operative credit instrument, 124 then such words as "full details to follow" not be inserted. ${ }^{125}$ Since the SWIFT User Handbook does not state that the words "full details to follow" disqualify the SWIFT message as an operative credit instrument, a bank may be led to assume that a message containing these words is the operative credit instrument unless the message contains specific language stating otherwise. ${ }^{126}$

sight or at a tenor, on the issuing bank or on the applicant for the credit or on any other drawee stipulated in the credit other than the confirming bank itself."

123. SWIFT User Handbook ch 4 at 4-1, Message Type 700/701.

124. UCP art 12 (c).

125. Id arts 12 (a) and (b) state, in relevant part:

(a) When an issuing bank instructs a bank (advising bank) by any teletransmission to advise a credit or an amendment to a credit, and intends the mail confirmation to be the operative credit instrument, or the operative amendment, the teletransmission must state "full details to follow" (or words of similar effect) or that the mail confirmation will be the operative credit instrument or the operative amendment .... .

(b) The teletransmission will be deemed the operative credit instrument or the operative amendment, and no mail confirmation should be sent, unless the teletransmission states "full details to follow" (or words of similar effect), or states that the mail confirmation is the operative credit instrument or the operative amendment.

126. The following are additional instances of conflicting procedures and definitions. SWIFT's guidelines and instructions pertaining to confirmations may preclude reimbursement by an advising bank that decides to "silently" confirm the issuing bank's irrevocable credit. A silent confirmation occurs when an advising or negotiating bank of a freely negotiable credit promises to purchase or negotiate beneficiary's draft drawn against the issuing bank. It also takes place when an advising or negotiating bank states in a communication to the beneficiary that it is willing to confirm an irrevocable letter of credit silent as to its confirmation. In the first case, the silent confirmation is nothing more than an agreement to purchase or negotiate a draft which can be entered into without letter-of-credit authorization. In the second case, the advising or confirming bank assumes the primary liability of an issuer and confirmer, and this liability cannot be assumed without the letter of credit's authorization. The second type of silent confirmation has become controversial precisely 
c. The contextual meanings of "operative credit instrument," "writing," and "signature." Similar instances of collisions or near collisions between SWIFT rules and the UCP are likely to arise and multiply unless each set of rules is placed in its proper context. SWIFT's context is that of interbank communications; its messages are designed for utilization solely by member banks. Member banks are entitled to expect from SWIFT speedy and secure communications, and, in exchange, they are bound to observe specified duties of diligence and good faith. In this interbank context, a SWIFT teletransmission of a Message Type 700 or 701 is, as suggested earlier, the operative credit instrument. In the same context, a receiving bank need hardly be reminded of the tacit incorporation of the UCP in the sender's telecommunication or of the operational meaning of "full details to follow." Moreover, while no member bank should expect a Message Type 700 to be signed, it should expect it to be authenticated. This expectation reflects the banks' willingness to abide by some SWIFT-inspired usages as binding custom. Accordingly, even if the UCP had not so declared, SWIFT users would treat the telecommunication of the documentary credit as a binding writing and the authentication of the message as the functional equivalent of a signature. The same is not true, however, in the receiving bank-beneficiary context.

Article 12 of the UCP gives binding effect to the interbank electronic letter of credit but fails to clarify that a SWIFT message is not the operative credit

because it is undertaken by banks that have not been requested to confirm the credit by the issuing bank. The UCP contain no prohibition against these silent confirmations and thus could be interpreted as allowing a silent confirmer's claim of reimbursement from the issuing bank. SWIFT's field 49 (Handbook ch 4 at 4-7), however, limits the confirmation instructions to the advising bank to the following: "confirm" (by which the confirmer is requested to confirm the credit), "may add" (by which the receiver may add its confirmation), and "without" (by which the receiver is not requested to confirm the credit). If SWIFT guidelines were to be given binding force, they could be interpreted as allowing reimbursement for confirmations only when the receiver was instructed to confirm or was allowed to add its confirmation.

Conversely, SWIFT field 41 (a) lists a form of payment referred to as "mixed payment," which is not included in UCP article 11 (a) among those available to the beneficiary of a documentary credit. (Article 1la of 1983 UCP states: "All credits must indicate whether they are available by sight payment, by deferred payment, by acceptance or negotiation.") If by "mixed payment," SWIFT means a credit payable partly at sight or by acceptance or negotiation, and partly by a deferred payment, a bank paying a letter of credit incorporating the UCP that does not specify such a form payment would be justified in rejecting it. Mutatis mutandis, SWIFT's directive requiring "the cancellation of a Documentary credit take the form of an amendment" (Swift Handbook ch 11 at 11 1), could also be easily at odds with a letter-of-credit stipulation. Assume, for example, that a bank issued a financial standby credit subject to revocation or cancellation upon the issuer's determination that the payment fund was depleted, or upon the applicant's or third party's certification of depletion. Following the SWIFT User Handbook, the bank, upon its determination of depletion or upon the applicant's or third-party certification, would have to handle the revocation or cancellation as an amendment. Yet, as an amendment, the revocation or cancellation would have to be accepted by the beneficiary before it became effective. See UCP art 10d. Predictably, the beneficiary may decide to reject the amendment, thereby preventing the revocation or cancellation of the credit. If this rejection is upheld, the issuing bank may become liable to the applicant for failure to follow his instructions and the letter-of-credit stipulations. The same problem occurs with annually renewable standby credits. Often the beneficiaries of these credits request an annual amendment of the credit to signify its validity for the upcoming annual period. By requesting this amendment, however, the beneficiary risks transforming a multi-year credit into a year-to-year commitment. 
instrument or amendment as far as the nonSWIFT-environment beneficiary is concerned. Neither does article 12 state whether an unsigned, paper-based transcription of the original SWIFT message is binding on the issuing bank. The banking practice is that a beneficiary can rely on a SWIFT message only once it becomes a "writing" in the traditional sense of the term-that is, once it has been reduced to a signed or otherwise authenticated paper-based document. ${ }^{127}$ In most cases, the receiving bank prints out the SWIFT message and adds whatever clause its software is programmed to print. Thus, in banking practice, a printout or hard copy of the SWIFT message can be the operative credit instrument for the non SWIFT-environment beneficiary. This dualism, requiring different "instruments," legal prerequisites, and sources of law, must be acknowledged and boundaries must be set.

The basic principle for setting the boundaries of paperless-credit law is that the environment, and not the presence of a beneficiary, determines which source of law is applied. Consider, for example, the case of a SWIFT receiving bank that is also the beneficiary of the letter of credit. If the demarcation rule were that the teletransmission ceased to be the operative instrument once the electronic message reached the beneficiary, the receiving

127. For a description of banking practices on the writings sent to intermediary banks and to the beneficiaries, and for an analysis of the conflict between UCP and UCC rules, see Kozolchyk, 8 George Mason U L Rev at 292-97 (cited in note 52). For definitions of a writing in the context of commercial and banking transactions, see UNCITRAL 1990 at 6,7 (cited in note 10):

[a writing is defined] . . . normally by reference to the mode of imposition on the medium rather than by reference to the nature of the medium itself. For example, under the Interpretation Act 1978 in the United Kingdom, (Interpretation Act 1978, Schedule 1)) the term writing includes typing, printing, lithography, photography and other modes of representing or reproducing words in a visible form, whilst section 1-201(46) of UCC provides that "written" or "writing" includes printing, typewriting or any other reduction to tangible form. It is probably the case that whenever a statute uses the word "writing" without a definition, the legislator originally expected the writing to be on a traditional piece of paper or some other physical medium emitting the words to be read directly by humans.

The definition of a writing has often been extended to include a telegram or telex, as in article 13 of the United Nations Convention on Contracts for the International Sale of Goods. In article 7(2) of the UNCITRAL Model Law on International Commercial Arbitration, the definition of a writing has been further extended to include "telex, telegrams, or other means of telecommunication which provide a record of the agreement." Article 4(3) of the draft Convention on the Liability of Operators of Transport Terminals in International Trade proves that "the document ... may be issued in any form which preserves a record of the information contained therein." A similar idea is expressed in the definition of "notice in writing" in article 1(4) (b) of the 1988 UNIDROIT Convention on International Factoring, in which a writing "includes, but is not limited to, telegram, telex and any other telecommunication capable of being reproduced in tangible form."

On the other hand, as pointed out by James E. Byrne, Electronic Trade Payment-U.S. Legal Perspective 47 (1987) (SWIFT/SIBOS conference paper), "there is nothing in either the term 'paper' or 'document' inherently containing the concept of an original or barring the description of a printout from electronic impulses as either a paper or a document." The same author points out that "[a]s to signature, authenticated or tested transmissions can be a symbol executed or adopted with present intention to authenticate a writing within the scope of (UCC) Section 1-201(39)." Id at 51. He adds that UCC $\S 5-104(2)$ expressly provides by way of example that "a telegram may be a sufficiently signed writing if it identifies its sender by an authorized authentication. The authentication may be in code and the authorized naming of the issuer in an advice of credit is a sufficient signing." Id at 52. 
bank in our example could not rely on the teletransmission and could only rely on a paper-based instrument. Such a rule would be at odds with banking practice. ${ }^{128}$ Thus the demarcation point should be determined not by the mere presence of a beneficiary, but by the recipients or beneficiary's environment. In a nonSWIFT environment, the operative instrument may be the signed or authenticated writing of section 5-104 of the UCC, or if the message were conveyed by a proprietary or value-added network, whatever its "master agreement" or system rules identified as the operative instrument.

d. The need for the reassertion of the primacy of the UCP. As far as the parties to the letter of credit are concerned, the UCP as transactional rules displace SWIFT as system rules. It could not be otherwise unless these parties considered the medium more important than their message. Primacy of the UCP over the SWIFT User Handbook does not mean that SWIFT cannot promulgate its own rules of diligence or that it cannot apportion or limit its liability for acts or events that take place in its environment. Rather, primacy of the UCP means that no SWIFT rule or procedure can grant rights or impose duties inconsistent with the UCP's. It also means that in the event of conflict, the UCP prevails.

\section{II}

\section{Electronic Reimbursements of Letters of Credit and Article 4A of the Uniform Commercial Code}

\section{A. The Scope of Article 4A and Letter-of-Credit Reimbursement Practices}

The electronic reimbursement of a letter-of-credit payment effected in the United States is subject not only to the UCP and SWIFT User Handbook, but also to articles 5 and $4 a$ of the UCC and to the United States Council on International Banking ("USCIB") Guidelines and Procedures for Bank-toBank Reimbursements. ${ }^{129}$ Since article 5 covers the entire spectrum of letterof-credit transactions (at least as that spectrum was envisaged when article 5 was enacted), its application to any phase of the credit transaction should be expected. This is not true with respect to article $4 \mathrm{~A}$, which is devoted to electronic fund transfers and purports to exclude letters of credit from its application. Indeed, Official Comment 3 to section 4A-104 calls attention to the limited scope of section 4A-103(a)(1)(i)-(iii). This limitation is based upon the unconditionality of the payment order that transfers funds electronically - that is, if the payment order is conditional, it is excluded from article 4A. In furtherance of this principle, the Official Comment provides examples of transactions intended to be both excluded and included:

[A] New York bank may have issued a letter of credit in favor of X, a California seller of goods to be shipped to the New York bank's customer in New York. The terms of

128. Phone interview with Dan Taylor (July 3, 1991), in which he indicated that receivingbeneficiary banks commonly rely on their computer records of the sender-issuer's letter of credit.

129. See note 135. The Guidelines apply to all USCIB member banks automatically; they apply only to those correspondent banks that agree to be bound by the rules. 
the letter of credit provide for payment to $\mathrm{X}$ if documents are presented to prove shipment of the goods. Instead of providing for presentment of documents to the New York bank, the letter of credit states that they may be presented to a California bank that acts as an agent for payment. The New York bank sends an instruction to the California bank to pay $\mathrm{X}$ upon presentation of the required documents. The instruction is not covered by $4 \mathrm{~A}$ because payment to the beneficiary is conditional upon receipt of shipping documents .... Although the payment by the New York bank to $X$ under the letter of credit is not covered by article $4 A$, if $X$ is paid by the California bank, payment of the obligation of the New York bank to reimburse the Califormia bank could be made by an article $4 A$ funds transfer. . . . For example, if the New York bank pays its reimbursement obligation to the Califormia bank by a Fedwire naming the California bank as beneficiary, payment is made to the Califormia bank rather than to $X$. That payment is governed by article $4 A$ and it could be made either before or after payment by the Califormia bank to X. ${ }^{130}$

Unfortunately, the separation between the fund transfer covered by article $4 \mathrm{~A}$ and the instruction to negotiate or pay a letter of credit covered by article 5 is not as clear-cut as is assumed by the above Official Comment. First of all, one must question the unconditionality of the payment order addressed to the "agents for payment" referred to in Official Comment 3 to section 4A-104. Several "agents for payment" exist in letter-of-credit law and practice, and many, if not most, of their payments are conditional. Depending upon the terms of the transaction, advising, confirming, negotiating, reimbursing, and paying banks can all be considered the issuing bank's agents for payment. Assume, for example, that the California Bank in Official Comment 3's example is an advising bank that was asked by the issuing bank to take up the beneficiary's documents and pay if they comply with the terms and conditions of the credit. As the Official Comment acknowledges, the advising bank's payment to the beneficiary is conditional and therefore beyond the scope of article 4A. Yet, despite the New York bank's use of FEDWIRE or CHIPS for purposes of reimbursing the California advising-paying bank, the New York bank's "direct" method of reimbursement ${ }^{131}$ still presupposes that the documents against which the California bank paid complied with the terms and conditions of the credit. If the documents did not comply, the issuing bank, after payment, would either debit the advising-paying bank's account (if

130. See UCC $\S 4$ A-104(3) comment 3 (emphasis added). Comment 4 to the same provisions elaborates on the distinction between "credit" transfers and "debit" Iransfers as follows:

In a credit transfer the instruction to pay is given by the person making payment. In a debit transfer the instruction to pay is given by the person receiving payment. The purpose of subparagraph (ii) of subsecton (a)(1) of Section $4 \mathrm{~A}-103$ is to include credit transfers in $4 \mathrm{~A}$ and to exclude debit transfers.

131. In this direct method of reimbursement, the issuing bank's promise of reimbursement is usually stated in the communication accompanying the operative credit instrument or in the operative credit instrument itself. It may also appear as an authorization to debit the account of issuing bank with the reimbursing bank in either of the above communications. This method of reimbursement is known as a "book transfer" because no physical (including electronic) movement of funds among banks is required. Dan Taylor describes the most typical form of direct reimbursement as follows: "Bank $A$ issues its credit and advises it to Bank B who is authorized to pay the credit. Reimbursement instructions for the paying bank are provided in the credit itself. Bank B advises the credit to beneficiary $C$. When Beneficiary $C$ presents documents to Bank B, Bank B pays the credit and claims reimbursement from Bank A." See Memorandum from Dan Taylor to Boris Kozolchyk (July 4, 1991) (on file with the Documentation Center of the University of Arizona College of Law) ("Taylor Memorandum"). 
such an account exists) or seek the return of its payment. ${ }^{132}$ The New York issuing bank's reimbursement via CHIPS or FEDWIRE, therefore, remains a conditional form of payment, although the condition is not precedent, but subsequent. Indeed, advising-paying banks use typical "condition subsequent" language in describing their right to reimbursement: reimbursement can be claimed "as long as the documents against which we paid are in compliance." 193

The "bank-to-bank" reimbursing bank is another "agent for payment" whose payment is also conditional. Unlike the method of reimbursement described in Official Comment 3 to section 4A-104, bank-to-bank reimbursement does not involve a direct payment by the issuing bank to the advising-paying bank. As an indirect method of reimbursement, it rather relies on an intermediary correspondent bank acting as the issuing bank's agent for payment or reimbursement of the advising bank.

\section{B. Article 4A and the USCIB Guidelines}

The bank-to-bank agent for payment is so ubiquitous in letter-of-credit practice that the USCIB ${ }^{134}$ found it necessary in 1981 to enact a set of procedures on bank-to-bank reimbursements, subsequently revised as Guidelines and Procedures. ${ }^{135}$ The banks involved in this reimbursement transaction are the issuing, reimbursing, and claiming banks. An issuing bank is a bank that "issued a Reimbursement Authorization under its letter of credit."136 A reimbursing bank is a bank authorized to effect reimbursement "pursuant to a Reimbursement Authorization issued by the issuing bank."137 And a claiming bank is a bank that negotiated, paid, or accepted drafts under a letter of credit and claims reimbursement from the reimbursing bank "under the Reimbursement Authorization issued by the issuing bank."'138

132. Id.

133. Telephone Interview with Dan Taylor (July 5, 1991).

134. On the USCIB, see note 9.

135. See the United States Practices and Procedures Governing Bank-to-Bank Reimbursements Under Letters of Credit (1981), revised in 1990 as United States Guidelines and Procedures Governing Bank-to-Bank Reimbursement under Letters of Credit (Feb 22,1990) ("Guidelines") (on file with the Documentation Center of the University of Arizona College of Law). Dan Taylor describes the bank-to-bank reimbursement as follows:

Bank $\mathrm{X}$ issues its credit and authorizes Bank $\mathrm{Y}$ to advise the credit to the beneficiary and pay the credit if properly drawn on. At the time of issuance of the credit, Bank $X$ provides another bank, Bank $Z$, with a reimbursement authorization telling them that Bank $Y$ has been instructed to claim reimbursement on Bank $Z$ and if they claim the reimbursement, Bank $\mathrm{Z}$ is to debit Bank X's account and pay Bank Y.

Taylor Memorandum (cited in note 131).

136. Guidelines art la (cited in note 135).

137. Id art $1 \mathrm{~b}$ (emphasis added).

138. Id art Ic (emphasis added). Dan Taylor characterizes the claiming bank's request for payment from the reimbursement bank as a debit transfer in accordance with the definition of debit transfer in 4A-104 comment (4): "In a debit transfer the instruction to pay is given by the person receiving the payment." Taylor points out that this definition should exclude bank-to-bank letter-ofcredit reimbursements from the application of article 4A. Taylor Memorandum (cited in note 131). 
The USCIB Guidelines provide for two types of reimbursement authorization. The first is issued by the issuing bank to the reimbursing bank and reimburses a claiming bank for its negotiation or payment under the letter of credit or its acceptance of a time draft drawn on the reimbursing bank. ${ }^{139}$ The second is described as a "separate, irrevocable undertaking of the reimbursing bank, issued at the request of the issuing bank, to a bank nominated in the Reimbursement Authorization to honor their claim(s) (sic) under such undertaking, provided that the terms of said undertaking have been complied with." 140

The italicized language makes clear that this reimbursement is predicated upon compliance with pre-established terms and conditions. In addition, article 9(a) of the USCIB Guidelines sets forth a major documentary condition precedent to the payment of sight claims: the claiming bank's claim for reimbursement "must be in the form of an original letter or teletransmission."141 Article 9(a) also forbids the use of such other documents as "the claiming bank's advice of payment, acceptance, negotiation or deferred payment to the Issuing Bank." 142 Such a condition precedent presupposes that prior to reimbursing the claiming bank, the reimbursing-paying bank examines the claim document or message and determines its appropriateness.

\section{Consequences of Applying Uniform Commercial Code Article 4A to Letter-of-Credit Reimbursements}

The application of article $4 \mathrm{~A}$ to the reimbursement of a payment or negotiation of a letter of credit creates serious problems. To begin with, article $4 \mathrm{~A}$ requires acts of diligence from the receiving bank that, while appropriate for electronic fund transfers, are inappropriate for the reimbursement of letter-of-credit payments. Consider, for example, article $4 \mathrm{~A}$ 's security procedures. Section 4A-201 defines a security procedure as one established by agreement between a customer (including a correspondent bank) ${ }^{143}$ and the receiving bank "for the purpose of (i) verifying that a payment order or communication amending or cancelling a payment order is that of the customer, or (ii) detecting error in the transmission or the content of the payment order or communication." 144 Section 4A-201 goes on to enumerate security procedures discussed earlier in connection with SWIFT, ${ }^{145}$ such as algorithms, encryption, and identifying words or numbers. The section concludes by asserting that "[c]omparison of a signature on a

139. Guidelines art 1d.

140. Id art le (emphasis added).

141. Id art 9a.

142. Id.

143. See UCC $\S 4 A-105(a)(3)$. Dan Taylor points out that there is often no relationship between the reimbursing bank and the claiming bank that would establish a customer relationship in a bankto-bank reimbursement transaction. Taylor Memorandum at 6 (cited in note 131).

144. UCC \& 4A-201.

145. See text accompanying notes 32-39. 
payment order or communication with an authorized specimen signature of the customer is not by itself a security procedure."146 These requirements and procedures are inconsistent with letter-of-credit reimbursement practice. As stated by Dan Taylor, the USCIB's executive director, in a recent memorandum:

\begin{abstract}
While many bank-to-bank reimbursement (authorizations) are communicated electronically, a large amount is communicated by mail. ${ }^{147}$ Section $4 \mathrm{~A}-201$ states that a comparison of a signature on a payment order or communication with an authorized specimen signature of the customer is not by itself a security procedure. Yet, with a mail bank-to-bank reimbursement this comparison is the only verification or authentication that exists . . . . The bank-to-bank reimbursement is, in fact, not a payment order but only an instruction to reimburse a claiming bank if the claim is received and, then, according to any conditions of authorization. ${ }^{148}$
\end{abstract}

A reimbursing bank, acting as an article $4 \mathrm{~A}$ receiving bank, must take into account that failure to carry out the section 4A-201 security procedures will determine who, as between the receiving bank and the sender or purported sender, will bear the loss resulting from a spurious or erroneous payment order. ${ }^{149}$ Moreover, section 4A-202 protects the receiving bank against a customer's allegation of an ineffective payment order only if the following requirements are met: (1) the receiving bank and its customer agree that the authenticity of the payment order will be verified by a security procedure; (2) the security procedure is "commercially reasonable"; and (3) "the [receiving] bank proves that it accepted the payment order in good faith and in compliance with the security procedure and any written agreement or instruction of the customer restricting acceptance of payment orders issued in the name of the customer." 150 The net result of sections 4A-201 and 4A-202 is that a reimbursing bank whose verification procedures do not qualify as commercially reasonable is unprotected against a customer's allegation of ineffective reimbursement authorization.

By the same reasoning, a letter-of-credit paying bank that does not follow sections 4A-201's and 4A-202's security procedures when wiring funds to a designated numbered account may find itself responsible for the consequences of an unauthorized or fraudulent transfer. Consider, for example, the case in which paying Bank A receives a letter on the beneficiary's stationery, signed by the purported beneficiary and asking that payment be wired to a numbered account at Bank B. The funds are wired by Bank $A$ to Bank B, where they are credited to the designated numbered account, which

146. UCC \$ 4A-201.

147. One large money center bank estimates that presently it receives approximately 83,000 reimbursement authorizations per year, of which 4,500 are mail authorizations. It also handled 17,000 amendments to these authorizations and 96,000 claims for reimbursement (including partial shipments and amended authorizations), and of these 6,000 were by mail. Telephone interview with Dan Taylor (July 2, 1991). If one divides the number of mail authorizations by the number of annual working days (250), this bank receives an average of 20 mail authorizations and 25 mail claims per day.

148. Taylor Memorandum at $6 \& 7$ (cited in note 131).

149. See Official Comment to UCC $\$ 4 A-201$.

150. UCC $\S 4 A-202(b)$. 
turns out to belong to the same fraudulent schemer who had appropriated the beneficiary's stationery and forged his authorization. While it may be argued that such a wire transfer is not an article $4 \mathrm{~A}$ payment order because it is a "debit" and not a "credit" transfer, the burden of proof on this issue would fall on the paying bank. ${ }^{151}$ If unsuccessful in its proof, the paying bank would be saddled with a risk it is not prepared to undertake as a mere paymaster of letters of credit. It should be remembered that unlike the bank customeroriginator of an electronic payment fund, who is usually well known to the bank issuing the payment order, the beneficiary of a letter of credit may not be well known to the paying bank.

Other consequences of applying article $4 \mathrm{~A}$ to bank-to-bank reimbursements can be equally serious. Section 4A-301, for example, states that the execution date of a payment order may be determined by instruction of the sender but "cannot be earlier than the date received, and unless otherwise determined, is the day the order is received." A bank-to-bank reimbursement authorization, however, seldom if ever states a fixed date for payment because the reimbursing bank will not know until the complying tender is paid by the claiming bank whether a claim for reimbursement will be made. ${ }^{152}$ In fact, the USCIB Guidelines discourage the statement of an expiration date in a Reimbursement Authorization. ${ }^{153}$ In contrast with article $4 \mathrm{~A}$ 's restrictive "payment date of the order," 154 the Guidelines provide the reimbursing bank with "a reasonable time to honor claims made to them by the Claiming Bank."'155 Similarly, section 4A-302(d)'s prohibition of deduction of charges for services and expenses is at odds with standard letterof-credit practice. ${ }^{156}$

One of the most serious consequences of applying article 4A to electronic letter-of-credit reimbursements or prepayments is the possibility of involving an innocent confirming bank in the issuing bank's violation of the law. ${ }^{157}$

151. UCC § 4A-207 (b) relieves the beneficiary's bank from liability when the payment order it received identified the beneficiary both by name and by an identifying or bank account number and the name and number identify different persons. As stated by subsection (1):

Except as otherwise provided in subsection (c), if the beneficiary's bank does not know that the name and number refer to different persons, it may rely on the number as the proper identification of the beneficiary of the order. The beneficiary's bank need not determine whether the name and number refer to the same person.

152. Taylor Memorandum at 8 (cited in note 131)

153. Article 4 of the Guidelines states in relevant part: "Therefore, while the loc must have an expiry date, the Authorization should not have an 'expiry date' except as indicated in article 5 herein. Reimbursing banks will assume no responsibility for expiry dates of Authorizations unless and to the extent expressly agreed to by them ...."

154. The "payment date of the order" is the due date for the beneficiary's bank in section $4 \mathrm{~A}$ $404(a)$.

155. Guidelines art 6 a (cited in note 135).

156. The Taylor Memorandum describes the letter-of-credit practice as follows: "If a credit states that all charges are for the account of the beneficiary and the reimbursement authorization is silent, the reimbursement charges will be deducted from the claim paid to the claiming bank. The claiming bank will often deduct its own charges from the proceeds paid to the beneficiary." Taylor Memorandum (cited in note 131).

157. Some of the following hypotheticals were part of a memorandum submitted by Professor James Byrne of George Mason University School of Law and this writer to Professors Robert L. 
Assume that Bank A has issued an electronic letter of credit in violation of the antiboycott-of-Israel regulations and has requested Bank B to confirm it as SWIFT. Simultaneously, Bank A has wired funds on behalf of its customer to Bank B's account via CHIPS, and the funds arrive first. Pursuant to sections 4A-209(b)(2) and 4A-403(a)(1)-(2), Bank B (known in article 4A as the "beneficiary's bank") ${ }^{158}$ has accepted the payment order, inter alia, when it has received the entire amount of Bank A's payment order. ${ }^{159}$ Accordingly, Bank $B$ is obligated to pay the beneficiary under section 4A-404(a). ${ }^{160}$ While it is clear that the payment may be stopped or enjoined as illegal, ${ }^{161}$ it is not clear whether the receiving bank incurs liability to the beneficiary if the payment is so stopped or enjoined. It is also unclear whether the confirming bank incurs liability under the antiboycott regulations for having "accepted" an order to pay an illegal letter of credit.

The preceding hypothetical problem highlights the danger of importing article 4A's notion of "acceptance" of the payment order into an article 5 letter-of-credit prepayment or reimbursement context. There is no equivalent in letter-of-credit law or practice to article 4A's "beneficiary's bank's" automatic duty of payment upon receipt of the payment order. Thus, whenever an issuing bank electronically transfers to a confirming bank the funds to pay a letter-of-credit beneficiary and this transfer is unaccompanied by what Official Comment 3 to section 4A-104 refers to as an instruction "to pay upon presentation of the required documents," both banks are at risk of having to honor the credit prematurely and wrongfully. If the funds arrive before the message requesting confirmation of the letter of credit, under section 4A-404(a), the (future) confirming bank becomes liable for payment to the beneficiary on the payment date of the order because it is acting as the "beneficiary's bank." 162 The arrival of the funds before the confirmation request is not an unusual situation in the letter-of-credit situation where a considerable number of credits are prepaid (not collateralized) prior to either issuance or confirmation.

In 1989 , as the draft of article $4 \mathrm{~A}$ was being considered for adoption, a possible solution was suggested to the many problems created by the uneasy

Jordan and William D. Warren, Reporters for article 4A, on July 7, 1989 ("Byrne \& Kozolchyk Memorandum") (on file with the Documentation Center of the University of Arizona College of Law). Professor Byrne was acting as Chairman of the ABA Task Force for the Revision of Article 5; this writer was USCIB Representative to the ICC for the revision of the UCP and member of the ALI Consultative Commission on Articles 3, 4, and 4A.

158. See UCC § 4A-103(a)(3).

159. Id $\S 4 \mathrm{~A}-209$ (b)(2) states: “(b) Subject to subsections (c) and (d), a beneficiary's bank accepts a payment order at the earliest of the following times: (2) when the bank receives payment of the entire amount of the sender's order pursuant to section $4 \mathrm{~A}-403(\mathrm{a})(1)$ or $4 \mathrm{~A}-403$ (a)2); or ...."

160. Id § 4A-404(a) states in relevant part: "Subject to Sections 4A-211 (e), 4A-405(d) and 4A405(e), if a beneficiary's bank accepts a payment order, the bank is obliged to pay the amount of the order to the beneficiary of the order...."

161. See, among others, Chuidian v Philippine National Bank, 734 F Supp 415 (D Cal 1990).

162. See UCC $\S 4 A-404(a)$ and contrast with id \$ 5-112. 
interaction among articles $4 \mathrm{~A}$ and article 5 of the UCC and the UCP. ${ }^{163}$ The solution was to add the following language to section 4A-104: "To the extent, however, that the funds transfer is connected with a letter-of-credit transaction, it is governed by article 5." The increasing uneasiness of the letter-of-credit community with the above-described problems warrants reconsideration of the suggested addendum.

\section{The Applicant Initiated Electronic Letter of Credit}

1. Procedure. The first attempts by individual banks (as distinguished from banking networks) to issue letters of credit electronically occurred in the early 1970 s. ${ }^{164}$ The raw data for the issuance of the letter of credit were fed by a paper tape into a rudimentary word processor. This word processor not only produced the text of the letter of credit, but also simultaneously credited or debited the appropriate bank accounts. ${ }^{165}$ The second (and present) stage in the process of "computerizing" letter-of-credit transactions commenced in the late 1970s. During this stage, it became possible for an applicant to prepare an electronic draft of the letter of credit at his place of business and to transmit it to the issuing bank for ultimate issuance. ${ }^{166}$ This stage was made possible by the development of software that allowed not only the creation of the letter-of-credit application in accordance with a preprogrammed format, but also its transmission to the issuing bank's computer. Since this method was designed for multiple issuances, it required a master reimbursement agreement between the applicant and the issuing bank. Upon execution of the master reimbursement agreement, the applicant was provided with security devices that validated his message and authorized the release of the letter of credit.

The draft of the electronic letter of credit generated by the applicant has many of the same features as the SWIFT letter of credit, including discrete

163. Professor Byrne and I proposed this approach to two Reporters for article 4A. See Byrne \& Kozolchyk Memorandum (cited in note 157).

164. Interview with Mr. Gad Janay (Jan 16, 1990) (notes on file with the Documentation Center of the University of Arizona College of Law). Mr. Janay is President of Complex Systems Inc. of New York, and is one of the most respected pioneers in the computerization of letter-of-credit transactions. Charles del Busto, on August 1, 1991, stated that in the early 1960s Leonard Black of Citibank experimented with quasi-electronic credits by "masking" customers' applications with the issuing bank's template. This was accomplished by superimposing the name of the bank, the necessary engagement clauses, and the space for the authorized signature, onto the customer's application, and then xeroxing the text onto safety paper to generate the original letter-of-credit instrument. This instrument was sent to the advising bank or the beneficiary via mail and in some instances by long-distance xerox to selected overseas branches for onward transmission to the beneficiaries. This process avoided re-keying all the information in the application into the credit text and reducing potential typographical and transmission errors.

165. Id.

166. The description in the principal text summarizes interviews during 1990 with the following New York City bankers: Messrs. James Mc Ginley and Don Smith at Citibank, Vincent Maullela at Manufacturers Hanover, and Joe Nielson and Scott McCoy at Chase Manhattan Bank. The text of these interviews is on file with the Documentation Center of the University of Arizona College of Law. Individual interviews will be cited only when the information was the product of that interview. 
fields tagged in accordance with a standardized format. ${ }^{167}$ The draft of the letter of credit also requires the use of a password and carries with it encryption devices. The applicant-initiated text is transmitted to the issuing bank's computer and is accompanied by an electronic signal or code for message authentication and customer identification. Thus, when an applicant logs in to the host computer at the issuing bank, a prompt in the system requests a password. Once the message has been authenticated by the password, most software programs require that the applicant type in his identification key or code number. This key is changed periodically and is subject to stringent security procedures, including the delivery of the key to the applicant by a special messenger or courier.

At some of the larger money center and regional banks, the applicant's electronic draft is received by a "host" computer whose function is to establish the authenticity of the computer-generated message. The host computer does not check for line-of-credit authorization or for any other substantive element of the credit. It merely establishes that the letter-ofcredit message contains the required security codes and that it was sent by an authorized applicant. Once this step is completed, the message is transmitted to the appropriate department for a substantive check. This check focuses on credit limits, proper formulation of the terms and conditions of the credit, and use of intermediary banks, whether as advising, confirming, negotiating, reimbursing, or paying banks.

In order to perform the substantive pre-issuance checks, the clerk logs the electronic draft of the letter of credit into his own computer terminal. There he "maps" all the data fields and creates the proposed text for issuance. As a rule, the incoming text is "field tagged" when it appears on the clerk's screen and requires a minimum of typing. Some programs allow the clerk to determine the insertions made by the applicant in the original format supplied by the issuing bank. As a rule, the clerk checks the applicant's text against UCP requirements, and where necessary, suggests changes to the customer. The accepted changes are noted in the clerk's log, and the letter of credit will await release until the applicant and the responsible bank official approve the issuance. Usually such an approval is coded and appears in a given part of the computer message. Often the applicant waits until he can examine a hard copy of the amended text before he gives his approval. After applicant approval, the bank clerk reviews the approved changes before requesting final approval. This is true even though the applicant and the bank clerk can check the bank's latest version of the credit by logging into the applicant's computer "account." In this respect, the current procedures are less automatic than

167. According to Scott McCoy of Chase Manhattan Bank, some of the computer programs used for these applicant-initiated issuances contain no field limitations on length. Interview with Scott McCoy (Dec 7, 1990) (notes on file with the Documentation Center of the University of Arizona College of Law). 
those that prevailed in 1986, which allowed an immediate release of the credit upon completion of "fail-safe" procedures. ${ }^{168}$

Phone verification of the applicant's approval of the final text provides the applicant with extra time for accepting his liability with respect to the "establishment" of the credit. Once the credit is approved by the applicant and the issuing bank, it is sent to the intermediary banks, usually via SWIFT, or to the beneficiary by cable, telex, or letter or in fewer instances, by computer-to-computer communications.

2. The Applicant-Issuing Bank Master Agreement. A review of master agreements currently in use ${ }^{169}$ reveals a threefold pattern of regulation of the applicant-issuing bank electronic letter-of-credit relationship. Some of the terms and conditions in these agreements are designed to protect the issuing bank's proprietary interest in the software licensed to the applicant. Another set of provisions encourages and protects what will be referred to as the safe usage of the software. A final group of provisions organizes the traffic of messages between the applicant and the issuing bank by specifying, among other things, the time of establishment of the applicant's instructions.

a. The issuing bank as a licensor of software. Master agreements characterize the applicant's use of the issuing bank's software as pursuant to a nontransferable, nonexclusive license or as a sublicense if the software is provided by a third party. As a licensee or sublicensee, the applicant is subject to a number of duties designed to protect the exclusivity and safe use of the software. Exclusivity is protected by: (1) specifying that only the designated issuing bank can be a recipient of the authorized messages and (2) limiting the messages to a list that includes applications for the issuance of letters of credit and instructions and inquiries concerning other letters of credit and related transactions such as guarantees to steamship companies or airlines to induce their release of goods. Exclusivity is also protected by prohibitions against the creation of additional copies of the software (except for a "back up" or archival copy) and by the duty of confidentiality.

b. The applicant's duty of safe use. The applicant's duty safely to use the issuing bank's software is found in agreement provisions that require that the applicant's personnel be trained in the use of the software and that the applicant give prompt notice of software malfunctions or defects. Some of the larger banks provide the applicant with user manuals and require compliance with the manuals' procedures in order to discharge the duty of safe usage. The observance of proper security procedures, part of the duty of safe usage, requires the issuing bank to provide the applicant with test codes and/or cipher booklets and authentication devices. Exclusivity as well as the safe use of the software are protected by the applicant's duty to locate the software in a

168. See Kozolchyk, 8 George Mason U L Rev at 292 (cited in note 52).

169. Four master agreements were reviewed, two from money center banks and two from regional banks. These banks wished to protect their privacy and therefore will remain anonymous. 
designated computer or computers and by his assumption of the risk of malfunction or miscommunication if the software is used outside his principal place of business. In addition, the applicant assumes responsibility for the accuracy of the message transmitted to the issuing bank.

Even though only one of the three master agreements examined made it clear that the above enumeration of the applicant's duties of safe usage was not exhaustive, experience suggests the wisdom of such a clarification. For example, the presence of computer "viruses" in the applicant's own software has become an increasingly difficult problem. ${ }^{170}$ These viruses, usually imported into the applicant's computer from "bulletin boards" and pirated software, impede or distort the applicant's teletransmission of data. Thus, future master agreements are likely to require that the applicant assume responsibility for a "virus-free" environment.

c. Rules of traffic. The master agreement rules of traffic have undergone a significant transformation since 1986. ${ }^{171}$ At that time, some of the largest money center banks prided themselves on the automation of their issuance process. Some of these banks encouraged the applicant to regard himself as the drafter of the letter of credit, subject only to fail-safe checks by the issuing bank. Current master agreements take a different tack, emphasizing the issuing bank's discretion in the ultimate issuance of the letter of credit. Some of these agreements characterize the applicant's communications as either "applications" or "requests for issuance." The agreements also contain rules on the finality of such requests and typically state that authenticated requests are final upon receipt. The request may not be revoked or canceled by the applicant unless the issuing bank consents. In legal parlance, the applicant's request for issuance is deemed established and therefore irrevocable as of the moment of receipt by the issuing bank. The issuing bank, in turn, is not obligated to act upon the applicant's request, but rather may exercise its discretion as to the issuance of the letter of credit.

d. Limitation of liability. Master agreements invariably limit the issuing bank's liability. Typically, the issuing bank is liable only for gross negligence or willful misconduct and is absolved of liability for acts of God, machine or computer breakdown or malfunction, and indirect, consequential, or special damages. Further, the issuing bank usually reserves a right of indemnification against the applicant for any unauthorized request or error in the transmission of the applicant's message if the transmission included a proper test-key verification or was automatically authenticated.

170. Telephone Interview with Vincent Maulella of Manufacturers Hanover Bank (April 29, 1991). James McGinley of Citibank had indicated in an earlier interview (May 10, 1990) that responsibility for the safe and secure usage of the software was one of the most sensitive issues in the bank-applicant relationship.

171. For a description of the practices prevailing in 1986, see Kozolchyk, 8 George Mason U L Rev at 285 (cited in note 52). 
This writer is unaware of any court decision on the issuing bank's liability as custodian of the applicant's electronic draft of the letter of credit or as a negligent issuer of the applicant-initiated electronic letter of credit. Lloyds Bank Plc. v. Lynch, ${ }^{172}$ although a SWIFT transfer of funds rather than a letterof-credit decision, sheds some light on the issuing bank's possible liability for damages. Plaintiff bank was retained by one of the defendants to transfer 100,000 dollars via SWIFT in connection with a proposed merger between defendants and Interleukin II, Inc. Plaintiff was supposed to have added the following message in the "Details of Payment" segment of the transfer of funds message: "INTER LEUKIN 2 FIRST OF FIVE INSTALLMENTS OF USD 100,000.00 EACH." As a result of a clerical error, the quoted words were omitted from the SWIFT message. Defendants' counterclaim alleged that owing to the mistake, the merger fell through and defendants failed to realize an estimated 100 million dollars gain in the value of Interleukin II stock.

In a motion for summary judgment on the counterclaim, the court reasoned that defendants had asserted a breach sufficient to saddle plaintiff with liability for defendants' lost gains. The court considered whether the delivery of the message as instructed would have consummated the merger. In other words, did the defendants have a cause of action against Interleukin II if it refused to merge? The court found that it was "incomprehensible that after such care as to draft and circulate a proposed Memorandum of Agreement, [Counterclaimant] Plaintiff Lynch would attempt to 'close' the transaction by such a method as the detail of payment line in a wire transfer." 173 The court distinguished between the cryptic terms of a wire transfer (a means of payment) and the terms and conditions of the underlying merger agreement. As to plaintiff's liability for consequential damages for a failure to exercise due care, the court relied on a "reasonably foreseeable" test. $^{174}$ In order to bear responsibility for failure of the underlying merger, "Lloyds must have reasonably foreseen that its failure with respect to the SWIFT transfer would lead to the resulting damage."175

The court found that Lloyds was neither a party to nor intimately involved in the failure of the underlying merger but rather was retained as a correspondent bank as part of a "routine international money transfer."176 Thereafter, the court added language that banks issuing letters of credit via SWIFT or otherwise should find worth remembering:

Lynch could have employed Lloyds in another capacity, providing the bank with independent knowledge of the underlying transaction and an understanding of the bootstrapping of the deal which was being attempted by the transfer's detail of payment provision. This would have alerted Lloyds to the potential liability as well as

172. 702 F Supp 157 (ND Ohio, 1988).

173. Id at 159 (parenthetical information added).

174. Id.

175. Id.

176. Id. 
providing it an opportunity to independently evaluate the attendant risks and to charge an appropriate fee. This was not done. ${ }^{177}$

Thus, despite the finding that consequential damages were not reasonably foreseeable in this case, the court left open the door to claims for consequential damages where, as in everyday issuances of letters of credit, the issuing bank is "with independent knowledge of the underlying transaction and an understanding of the bootstrapping of the deal."

\section{E. Facsimile Letters of Credit and Credifax Rules}

Facsimile (fax) transmissions of applications for the issuance of letters of credit and subsequent fax issuances have become quite popular. The fax medium is not paperless, but it combines the speed of a telecommunication with the convenience of paper. ${ }^{178}$ Yet fax communications, unlike SWIFT's, are not part of a system or network, but are open to anyone with a fax machine and connected telephone line. This explains why the bankers' main concern with faxed letter-of-credit or application messages is their lack of security. Many faxes, like General MacArthur's old soldier, simply fade away, leaving no trace of their former contents. Thus, if a fading fax document were to be used as an original, its enforcement would soon become uncertain and useless for audit trail purposes. Some fax machines produce permanent copies, but each of these copies, aside from being able to qualify as the original operative credit instrument, is also highly insecure. Assuming that it was not a total fabrication, the original message could have been easily forged, cut, pasted, and recomposed. Thus the validity of the signature or of other authentication devices in a faxed operative credit instrument cannot be reliably established unless the message were subjected to sophisticated enciphering and authentication procedures that are unsuited, as of this writing, for widespread use. ${ }^{179}$

The popularity of faxed applications and letters of credit prompted the International Cargo Handling Co-Ordination Association ("ICHCA") to propose the adoption of its "Credifax" rules to the ICC Banking Commission during its 1990 meeting in Hamburg. ${ }^{180}$ These rules were promptly rejected

177. Id.

178. A fax machine enciphers the image of the message sent because it digitizes it (a form of enciphering) and translates it into sound. This sound is, successively, digitized by the phone company and de-digitized by the fax machine at the receiving end of the message. It is at this end where the paper-based, graphic version of the message is produced.

179. The author is indebted to Gad Janay, one of the premier developers of letter-of-credit software and technology for his evaluation of the fax and optical imaging media. According to $\mathrm{Mr}$. Janay, only banks such as Citibank and Bankers Trust which have their own communications network can engage in the kind of enciphering and authentication of fax messages that might make them more secure. Yet, aside from the slowness in the communication that such security measures would introduce, fax messages outside that network would remain highly insecure.

180. See Summary Record of the June 28, 1990 Banking Commission meeting in Hamburg, ICC Doc 470/629 (July 27, 1990). See also the ICHCA request for adoption of Credifax in ICC Doc $470 / 590$ (Nov 22, 1989). The text of the proposed rules (hereinafter referred to as "Credifax rules") follows:

(1) In accordance with formal instructions by the applicant for a documentary credit, the documents of which are to be telefaxed, the issuing bank issues a credit specifying the 
by the Commission, and in this writer's opinion, justifiably so. To begin with, they were poorly drawn. While they validate the issuance of "a credit specifying the certified transfer of all documents from bank to bank by telefax" upon "formal instructions by the applicant,"181 they do not clarify the meaning of "formality" and "certification," especially in connection with applicable law. And unless these terms are given uniform meanings, their variation in different national laws would render the Credifax rules useless.

In addition, the Credifax rules would confer the power to issue the Credifax letter of credit not upon the party who assumes liability thereunder (either the issuing or confirming bank) but upon the applicant for the credit. Bankers could not abdicate such a power without risking serious losses. ${ }^{182}$ Finally, the Credifax rules would do nothing to induce greater security in the use of the telefax medium. The mere insertion of words such as "subject to the telefax transfer procedure" 183 or the applicant's willingness to accept on a temporary basis the photocopy of the telecopy of a specified document ${ }^{184}$ would not induce or encourage the utilization of safer procedures of telecommunication.

The rejection of the Credifax rules by the Banking Commission serves as a warning of the need to address the issues of security of the teletransmissions and consistency with the differing laws on formalities, certifications, and authentications of messages. No doubt much ground would have to be covered, but the task is inevitable. For unlike the SWIFT rules, the rules on faxed messages apply to an open environment and to an unlimited number of users.

certified transfer of all documents from bank to bank by telefax, the transport document should be, in such a case, issued in behalf of the issuing bank.

(2) All documents, including the transport document (original bill of lading) should bear the mention: "subject to the telefax transfer procedure."

(3) The bank of the beneficiary transfers by certified telefax to the issuing bank all the documents of the credit. The original documents should be mailed as soon as possible.

(4) The issuing bank hands over to the applicant for the credit:

(a) a photocopy of the telecopy of the bill of lading duly endorsed as well as photocopies of the telecopies of the other documents;

(b) a commitment vis-à-vis the carrier not to use the full set of bill of lading endorsed by the bank and the importer.

(5) When collecting the photocopies mentioned under (4) above, the applicant for the credit (importer) agrees to accept without any reservation the original documents that the issuing bank will given (sic) him as soon as they are received, except the bill of lading.

The bill of lading will be handed over to the carrier within a maximum period of three months.

181. See Credifax Rules $\S$ (1) (cited in note 180) (emphasis added).

182. As stated by Charles del Busto, Chairman of the Banking Commission during the 1990 Hamburg meeting:

The option of having documents transmitted via fax was a condition that could be allowed when a letter of credit is issued but . . . it had to be agreed by the issuing bank, the confirming and the beneficiary. However, the ICC could not endorse the Credifax rules because of the inherent dangers in using fax transmissions and the ease with which such documents can be tampered with ... .

ICC Doc 470/629 (cited in note 180 ).

183. See Credifax Rule 3 (cited in note 180).

184. See id Rule 4. 
III

\section{Paperless “Documents of Titze"}

\section{A. Introduction}

The documents usually required by letters of credit have either informational or title-transferring functions. The data in an informational type of document may include the description of the goods, the listing of the terms and conditions of insurance coverage, or the certification of volume, weight, health, or quality. Considerable progress has been made on a uniform layout and standardized text for the customs' invoice and possibly other informational documents. ${ }^{185}$ The trading nations' adoption of the United Nation's syntax for electronic business and administrative messages ("EDIFACT") 186 should make it possible to transmit many of the informational messages cheaply and reliably from beneficiaries' and third parties' places of business to banks.

Computer and telecommunications technology has also attempted to incorporate the three main functions of the ocean bill of lading (receipt of the goods, contract of freight, and document of title) into telecommunicated messages. ${ }^{187}$ As a result of this technology, several types of paperless bills of lading are currently in use. Most of these bills, however, are just carrierissued receipts. Only a few of the paperless bills currently in use can act as documents of title to the merchandise, and even fewer qualify as negotiable documents of title.

The fact that the negotiable-document-of-title function has not yet been fully incorporated into a paperless bill does not mean that paperless bills have no banking value. A paper-based ocean bill of lading is valuable to banks for both its informational and its document-of-title functions. As an informational document, it attests to the carrier's receipt of the goods at a given time and place, to the apparent state of the goods when received, and to

185. See, generally, Bergsten \& Goode, eds, Trading With EDI at 72-96 (cited in note 55). See also U.N. Commission on Int'l Trade Law, U.N. Trade/WP.4/R.590, United Nations Standard Message ("UNSM") for Formal Trial Customs Declaration Message: A proposed UNSM Customs Declaration Message that will permit the transfer of information from a consignor/exporter or a consignee/importer to a customs administration to effect the necessary declaration. An exporter may also consider sending the message to an importer as the basis of the import declaration in the country of import. For the layout key of trade documents, see U.N. ECE/Trade/137, G.E. 81 -32329 (Nov 1981) and International Organization for Standardization (ISO), EDIFACT Application Level Syntax Rules, ISO 9735:1988(E).

186. According to Roos, "[t]he UN/EDIFACT syntax rules set the standards for structuring data into segments, segments into messages, and messages into a transfer (interchange)." Roos, in Thomsen \& Wheble, eds, Trading with EDI at 53 (cited in note 55). For a description of EDIFACT efforts until 1990, see id at 53-60. Skeptics doubt that progress on standardization, beyond the present stage, is in the offing. One such skeptic recently told this writer that "if a dictatorial government cannot get all its industrial, financial, and commercial people to agree on EDI standards, how could you achieve such agreement in pluralistic societies and on a worldwide basis?" Nevertheless, despite the large number of inconsistent proprietary standards, more and more large businesses in major trading centers are accepting the inevitability of a uniform standard.

187. The following discussion in the principal text summarizes descriptive and analytical materials in Boris Kozolchyk, $23 \mathrm{~J}$ Maritime $\mathrm{L} \&$ Commerce at 161 (cited in note 79). 
the loading of the goods on board the (specified or unspecified) vessel. It is also true that as a negotiable document of title, it is valuable collateral, as it allows quick, easy, and inexpensive possession and resale of the cargo. Nowadays, however, few banks rely primarily on the collateral value of bills of lading when deciding whether or not to issue or to confirm a documentary credit; most rely more on the applicant's creditworthiness than on the cargo's market value.

\section{B. Paperless Receipts of Lading}

1. Introduction. The sea waybill, the air waybill, and the rail consignment note function as receipts of the goods by the sea, air, and rail carriers and also as informational documents. Unlike documents of title, these bills do not have to be presented to the carrier in order to obtain possession of the goods. The consignee of an air, sea, or railroad bill of lading needs only to identify himself to obtain possession. Nonetheless, since these receipts are often needed before the arrival of the goods to expedite their release, they can be transmitted electronically to the consignee or "notify party." And as long as their layout is uniform and their text is structured and standardized, they can be transmitted to anyone, including customs officials and banks, using the same EDI software.

In addition to allowing the ship to unload immediately upon arrival (thereby reducing the time and cost of unloading, processing, and warehousing of the cargo), the sea waybill also allows the consignor to vary his delivery instructions during the carriage. This feature can be useful when buyers suddenly become insolvent or when unfavorable market conditions require re-routing of the cargo. Roughly fifty percent of the North Atlantic trade relies upon the sea waybill, although it seems more popular with Scandinavian-initiated westbound traffic than with North American-initiated eastbound traffic. ${ }^{188}$

2. The Scandinavian Data Freight Receipt. In 1971, the Atlantic Container Lines ("ACL"), one of the world's largest container carriers, introduced a sea waybill labeled Data Freight Receipt ("DFR") for its North Atlantic shipments. As with the air waybill, the DFR eliminated the need to send paper documents with the shipment. All that was needed was a computer at each end of a dedicated phone line and software to allow computer-tocomputer communications. ACL communicated the issuance of the DFR to ACL's office at the consignee's place of business, in conjunction with which it separately sent an arrival notice and manifest. The goods were delivered

188. The materials in the present and following section on the data freight and cargo key receipt were obtained in large measure from interviews conducted by this writer in Gothenburg, Sweden on June 29,1990, with Messrs. Peter Lyon of Transagency Inc., Hans E. Laessker, Esq., Legal Advisor to Atantic Container Lines ("ACL"), and Soren Lonnartesson of SWEPRO. (Notes on these interviews are on file with the Documentation Center of the University of Arizona College of Law.) The author is most grateful to the interviewees for sharing their time and knowledge and to Professor Kurt Gronfors of Stockholm University for having arranged these interviews. 
upon either the consignee's or the notify party's identification, and delivery did not require presentation of the arrival notice.

As with the air waybill, the DFR was non-negotiable. It acknowledged receipt only for shipment and not for on-board loading. Its text also differed sharply from the traditional ocean bill of lading's because it lacked the terms and conditions of carriage, including the customary disclaimers of liability. Since the DFR was not a document of title, but merely a receipt and notice of shipment, it did little to assure the consignee or bona fide purchaser of the goods that the shipper would not resell or reroute the goods in transit. Neither did it allow a bank to acquire a perfected security interest in the cargo.

3. The Cargo Key Receipt ("CKR"). As with the Scandinavian DFR, the cargo key receipt ("CKR") provided an arrival notice given either to the consignee or to designated notify parties. Unlike the DFR, the CKR contained a "no disposal" (also known as "no disp") clause expressly agreed to by the shipperconsignor and the carrier at the moment of issuance of the CKR. The CKR named the third-party creditor as consignee and the buyer as notify party; no other parties participated in the transaction. The CKR, therefore, was designed as a closed transaction that precluded negotiation of either the CKR or the master bill of lading.

The conceptual basis of the CKR was the conveyance of the seller's right to control the goods while in transit to the secured creditor. This is a "negative" right because its object was not to retain permanent possession for the seller, but to prevent the buyer's acquisition of possession. While Professor Gronfors has traced the roots of this right to the Germanic Sperffunktion, ${ }^{189}$ similar rights in our day are both conveyed by the transfer of the "shipper's" copy of the air waybill and retained by unpaid sellers under section 2-705 of the UCC. ${ }^{190}$ By means of the "no disp" clause in the CKR, then, the shipper-consignor agreed to a known (although not widely used) method of creating a security interest-that is, the conveyance of his negative possessory right to a consignee who was either an issuing or a confirming bank. This possessory right was limited and partial because rights similar to those of the consignor inured to any other holder of the "original" CKR (if such there was). In addition, the right of control conveyed by the "no disp" clause to an issuing bank, for example, could not interfere with the carrier's normal operations of storage, loading, and unloading, although it did permit stoppage in transit, withdrawal of the goods at the departure pier, unloading of the goods already placed on board the vessel, and warehousing or

189. See Kurt Gronfors, Towards a Transferable Sea Waybill: An Answer to Shortcomings of Bills of Lading, A Report to the Hamburg Symposium on Sea Waybills 77 (Oct 2, 1987) (unpublished report on file with the Documentation Center of the University of Arizona College of Law).

190. UCC $\S 2-705(1)$ in relevant part states: "The seller may stop delivery of goods in the possession of a carrier or other bailee when he discovers the buyer to be insolvent (section 2-702) ..." 
rerouting of the goods, including their delivery to a consignee other than the one indicated in the ocean bill. The buyer-importer, who, as indicated above, was usually designated as the notify party of the CKR, was one of the two parties to receive the arrival notice, the other being the consignee-creditor. When the buyer-notify party paid the amount owed to the issuing bank, it received the latter's authority to claim the goods from the carrier.

The CKR reduced the use of paper documents considerably and provided a means to secure the interest of the distant issuing bank in an almost paperless bill of lading. The question should be asked then, why was not such a seemingly logical scheme acceptable to banks, especially in the United States? The answer is that the issuing bank was not sufficiently protected as an assignee of the consignor's negative possessory rights. The CKR did not qualify as a perfected security interest under the UCC. Section 9-304(3) of the UCC requires that a security interest in goods in the possession of a bailee who has not issued a negotiable document of title be perfected by notifying the issuance of document in the name of the secured party. Alternatively, it can be perfected by notifying the bailee of the secured party's interest or by filing as to the goods. ${ }^{191}$ None of these acts was performed in the CKR transaction. Moreover, since the CKR was not a document of title, the bank had a security interest not in the goods themselves, but rather in the consignor's right of control over the shipment. Since this right qualifies as a "general intangible" under the catch-all definition of UCC section 9-106, a security interest therein could not be perfected by the issuance of the CKR by the carrier-bailee, as would be the case under UCC section 9-304 if the CKR were a negotiable document of title. An appropriate filing of the security interest is, in this writer's opinion, required unless the security interest is characterized as arising "solely under the Article on Sales," a characterization that ill fits the CKR transaction. ${ }^{192}$ The lesson derived from the banks' rejection of $\mathrm{CKR}$ is that a paperless conveyance of rights to cargo will have to involve a more effective security interest than the seller's negative possessory rights.

191. See id § 9-304(3).

192. Id § 9-113 states that as long as the seller's debtor is not in possession of the goods no security agreement is necessary and no filing is required. Yet, the article 2 security interest predicated upon UCC $\$ 2-705$ 's right of stoppage of delivery in transit is narrower in scope than the right conveyed to the bank by the CKR. Section $2-705$ applies only when the seller discovers the buyer's insolvency or when the buyer repudiates or fails to make a payment due before delivery of if for "any other reason the seller has a right to withold or reclaim the goods." Before such a time, the right, and consequently the article 2 security interest, does not exist. Assuming, then, the need to file and assuming proper filing under UCC $\$$ 9-401, the bank's interest could still be inferior to that of a buyer of the goods in the ordinary course of business or of consumer goods under UCC $\$ 9-307$ if somehow the goods subject to the bank's control became inventory or consumer goods. Furthermore, even if the bank's interest was deemed to apply to the buyer's inventory, a purchase money security interest in the same inventory would, in accord with UCC $\S 9-312$, be prior to the bank's. The net effect is that even if the bank obtains possession of the goods by means of its security interest on the right of control of the shipment, it could very quickly lose its possession to third-party creditors or buyers. 
4. Privity of Contract, Abstraction, and the English Sea Waybill. Privity of contract has remained a major obstacle to the modernization of English billof-lading law. ${ }^{193}$ Under the nineteenth-century English law, the rights under the contract of freight still are transferred only to a person "to whom the property in the goods passes upon by reason of endorsement."194 This requirement causes a problem for sea waybills as much as for traditional bills of lading. Where property to the goods does not pass to the consignee of the bill of lading or passes independently of the bill of lading or where the transfer of the bill of lading does not cause the transfer of title, neither the consignee nor the holder can claim the goods from the carrier. ${ }^{195}$ Thus, if English sea waybills were ever to be used as documents of title-that is, conveying at least as much of a property right to the goods shipped as the consignor had (as is the case with "straight" bills under the statutory law of the United States) - these sea waybills would have to be freed from the privity restriction. 196

In addition, bill-of-lading law would have to be freed from other contractual and agency law restrictions such as the ultra vires doctrine enunciated in the landmark English case of Grant $v$. Norway. ${ }^{197}$ In this case, a master who signed a bill of lading for twelve bales of silk that had not been shipped was held to have had no authority to issue such a bill, and this rendered the bill unenforceable. The English and Scottish Law Commissions recently recognized the need to remove this obstacle and thereby to free the carrier's obligation to deliver the goods from the relationships between the shipper and the carrier or the carrier and other carriers or agents for carriage. In accordance with the Commissions' recomendations, a bill of lading stating that the goods had been shipped or received for shipment "and in the hands of a lawful holder, should be conclusive evidence against the carrier of such shipment or receipt."'198

193. See English Law Commission No 196 and Scottish Law Commission No 130, Rights of Suit in Respect of Carriage of Goods by Sea (1991) ("Law Commissions' Report").

194. The English Bills of Lading Act, An Act to Amend the Laws Relating to Bills of Lading, $1859,18 \& 19$ Vict ch $111 \S 1$ (stating that every consignee named in the bill of lading and every endorsee of a bill of lading could assert contractual rights of action against the carrier but only if the interest in the goods passed to the consignee of the consignment or endorsement).

195. See Law Commissions' Report at 5 (cited in note 193).

196. In the law of the United States, a straight bill of lading is, although not negotiable, a transferable document and as such functions as a document of title in accordance with the Pomerene Act, 49 USC $\$ \S 109 \& 112$. As set forth in relevant part of 49 USC $\$ 112$ :

A person to whom a bill has been transferred, but not negotiated, acquires thereby as against the transferor the title to the goods, subject to the terms of any agreement with the transferor. If the bill is a straight bill such person also acquires the right to notify the carrier of the transfer to him of such bill and thereby to become the direct obligee of whatever obligations the carrier owed to the transferor of the bill immediately before the notification

197. (1851) $10 \mathrm{CB} 665$.

198. Law Commissions' Report No 5 at 40 (cited in note 193). 


\section{The Negotiable Electronic Bill of Lading.}

a. SeaDocs registry limited. It is quite common in the oil spot market to sell one oil cargo repeatedly during a trading day to traders in different parts of the globe. SeaDocs Registry Limited ("SeaDocs"), a London cooperative venture between Chase Manhattan Bank and INTERTANKO (an association of oil tankers), was intended to bring about the telecommunicated negotiation of bills of lading issued in connection with oil shipments. Unfortunately, while SeaDocs was the first serious attempt to fashion a negotiable electronic bill of lading that proved to be technically feasible, it was unsuccessful and was closed within one year of its inauguration in $1986 .{ }^{199}$

SeaDocs acted as a depository-custodian of the paper-based original bill and as a registry of bill-of-lading negotiations. The registry was to act as an agent for the parties' (sellers' and buyers') endorsement of bills and for the delivery of the final version of the paper-based bill of lading with which to claim the goods from the carrier. Its operative scheme was as follows: (1) A bill would be issued by the carrier in the traditional negotiable, paper-based manner, but it would be taken out of circulation immediately after issuance, and the original bill would be sent to SeaDocs by courier for safekeeping in its vault. (2) Upon delivery of the original bill to SeaDocs, the shipper would receive a code or test key equivalent to the personal identification numbers ("PINs") provided by banks for use with automated teller machines. (3) When the bill was negotiated, the shipper or his endorsee would notify SeaDocs by computer of the buyer-endorsee's name and also provide the endorsee with a portion of his test key. (4) The seller's message would be tested by SeaDocs before it accepted the communication from the endorseebuyer, and the endorsee-buyer's message would then be tested and accepted if it contained the portion of the original seller's test key. (5) Compliance with the various checks having been confirmed, the name of the new owner of the bill would be recorded in the registry (this name would also be entered on the documentary bill of lading deposited in SeaDocs' vault). (6) Any endorsement reflecting the bill's negotiation would be effected by SeaDocs as an agent for both endorser and endorsee. (7) When the goods arrived at the port of discharge, SeaDocs would transmit an identifying code number to the ship's master and would send a similar identifying code to the last endorsee or owner of record of the original bill. (8) Using this number, the last endorsee or owner of record would obtain the printout of the hard copy of the final bill of lading with which to claim the goods.

199. According to the Oil Daily, the idea for SeaDocs came from Per Gram, a Norwegian maritime lawyer, as a result of a notorious case involving the shipment of a cargo of Italian gasoil to a trader in Northern Germany in 1978. Marvin Murphy, Energy Finance Report, Oil Daily (June 10, 1985). The cargo was delivered by the captain of the Norwegian vessel "Sagona" before receiving the original bill of lading, and this delivery triggered a number of lawsuits by various claimants to the oil. Per Gram circulated a paper proposing a solution to the Sagona type of problem. "As a result of a study started by Chase, a system for handling documents was scribbled on the back of an envelope at the hotel lobby in Norway." Id. Several reasons have been adduced for its lack of sucess. One of the most frequently heard is that the cost of insurance was prohibitive and that not enough users expressed a continuing interest. 
Despite its demise, SeaDocs proved that an international, centralized, largely electronic bill of lading was technically feasible. From the standpoint of the paperless letter of credit, its most important lesson was that unlike the DFR, the CKR, and the English sea waybill, SeaDocs' PIN conveyed rights to the goods equivalent to those conveyed by a negotiable bill of lading that were enforceable as of the moment of the transmission of the appropriate messages by SeaDocs.

b. The comité maritime international's ("CMI's") "private key." The rules for electronic bills of lading adopted in 1990 by the $\mathrm{CMI}^{200}$ are the most sophisticated attempt to date to regulate open-ended, computerized issuance and negotiation of bills of lading. Unlike the SWIFT rules, the CMI rules can apply to any contracting party willing to abide by them. As optional rules, however, the CMI rules require that the parties to the electronic bill of lading specify the application of the rules in the "master" or in individual agreements.

The main feature of the CMI rules is the creation of an electronic bill of lading not by a centralized entity such as SeaDocs but by the carrier, which also acts as a registry of negotiations. Accordingly, the CMI electronic bill of lading can be issued by as many carriers as have the necessary hardware and software, and it can be "endorsed" by as many endorsees as have the same facilities. The device that makes such issuance, endorsement-negotiation, and registration possible is the "private key." The private key, in the words of one of the CMI draftsmen, is "akin to a single transaction personal indentification number."201

The CMI's private key operative scheme is as follows: (1) Upon receiving the goods, the carrier electronically sends to the shipper or the party designated by the shipper a "receipt message" containing a description of the goods and reservations by the carrier on the state of the goods. (2) The recipient confirms receipt of the message to the carrier, and following this confirmation, the carrier provides him with the private key. (3) Depending upon the specific system in use, the shipper and subsequent holders of the electronic bill of lading receive a password to access the carrier's computer network and/or an identification number and a private key. (4) The shipper or subsequent sending party then inputs the electronic address of the carrierreceiving party, and, as with telex messages, each party to the transmission sees the other party's address as the electronic "handshake" takes place. (5)

200. Rules for Electronic Bills of Lading (Comité Maritime International, 1990) (“CMI Rules"). For a published version of these rules, see Letter of Credit Update 33 (June 1990). The final version of the CMI Rules was published in Letter of Credit Update 21-31 (April 1991). The description of the operation of the CMI private key is mostly taken from a Memorandum of March 1, 1991 to this writer by George F. Chandler III, of the law firm of Hill, Rivkins, Loesberg, O'Brien, Mulroy \& Hayden, one of the CMI rules draftsmen ("Chandler Memorandum"). The writer is very grateful for Mr. Chandler's most helpful memorandum.

201. Chandler Memorandum at 8 (cited in note 200). CMI Rule 2(f) defines the private key as "any technically appropriate form, such as a combination of numbers and/or letters, which the parties may agree for securing the authenticity and integrity of a Transmission." 
After the security procedures are satisfied and the message is sent, the private key is used by the shipper or subsequent holders to verify the authenticity of the message. Thus, even though a fraudulent sender may know how to access the network and establish a valid identity, he cannot obtain possession of the goods without the use of the private key.

In an attempt to avoid multiple transfers of the same bill, the private key itself is rendered nontransferable. If a holder nonetheless transfers his private key, the carrier will be responsible for delivering the goods only to the party to whom it issued the last valid private key. The carrier will be liable for misdelivery, however, if it issues similar private keys or breaches the private key security safeguards. Unlike the CKR and SeaDocs procedures, which require presentation of a paper-based bill or authorization to obtain release of the goods, the private key is supposed to function as the equivalent of the negotiable ocean bill of lading. Its lawful use entitles the holder to the delivery of the goods.

When conveying the right of control and transfer, a holder of the private key relies on the same method of notification by which he became a holder. He will initiate the message to the carrier and will need to await the carrier's confirmation of its reception before the transfer process can be set in motion. Following confirmation, the carrier transmits the receipt message (possibly containing some such updating as loading on board the vessel) to the new holder. Upon confirmation of the reception of the carrier's message by the new holder-a confirmation that includes his acceptance of the right of control and transfer-the carrier will cancel the current private key and will issue a new private key to the new holder. In order to effectuate delivery of the cargo, the carrier notifies the holder of the place and date of intended delivery. Once so notified, the holder is obligated to nominate a consignee and to give delivery instructions to the carrier with verification by private key. Delivery of the goods by the carrier pursuant to these instructions automatically cancels the private key.

Bankers cannot visualize how telecommunications between strangers can be accomplished without incurring a high risk of fraud. They prefer the security of uniform log-in procedures, message numbering, error checking, encryption, record retention, uniform formats, and message self-auditing associated with SWIFT procedures. From a legal standpoint, it is doubtful whether the private key procedure can function as a negotiable bill of lading. The transferee's rights in the private key procedure depend upon both issuance of a private key and the transferee's acceptance of the right to control. Yet the transferee's acceptance of the right to control is based upon the information in the receipt message transmitted by the carrier or by someone purporting to be the carrier. Accordingly, it is not clear what rights are accepted by the transferee; relying upon fraudulent information, he may have accepted nonexisting rights. Meanwhile, the carrier may issue the private key to the transferee in the belief he has accepted a genuine receipt message. The rights incorporated into the private key, then, depend not only 
on the lawful acquisition of the private key, but also on the text of the carrier's valid receipt message. And while no carrier would want to be bound by terms and conditions other than those on the receipt message it sent, no transferee would want to pay for an electronic bill whose terms and conditions are other than those he received. This difficulty cannot be overcome by a stipulation that the receipt message and the private key together are the equivalent of a paper-based negotiable bill of lading. For as a rule, the creation of negotiable documents of title is a prerogative reserved solely for the legislature. ${ }^{202}$

The problem of unreliable receipt messages illustrates the need not only for a consistent, self-sufficient, and nonseverable obligational message, but also for a reliable entity that either issues or certifies the issuance of such a message. Traditionally the entity entrusted with these functions is a centralized registry. Centralized registries, regardless of legal system, have proven essential for paper-based transfers and encumbrances of valuable property. A fortiori, such registries are all the more indispensable for electronic transfers or encumbrances. A centralized registry, à la SWIFT, relies on more stringent security requirements than does the individual carrier-CMI registry. And by spreading the cost of security and insurance among a much larger number of users, the centralized registry makes the risk of fraud more manageable. In addition, a centralized registry is the only legal institution capable of providing requisite notice to the world at large.

It is true that much of the requisite notice to potential purchasers of paperbased documents of title or to creditors relying on these documents as collateral has been provided by the possession of these documents, as one may reasonably assume that the possessor, by the mere fact of his possession, is likely to have significant rights in the documents. Once the document of title becomes intangible and invisible, however, possession, having been rendered metaphysical, is no longer apparent and thus no longer serves a notice function. The only effective notice for electronic transfers and encumbrances, then, is that provided by a widely accessible registry. With such a registry in place, a problem such as the incompatibility between the carrier's actual receipt message and the message received by the transferee would be considerably diminished. The registry would assume responsibility for a breach of its security measures and for negligent or fraudulent transmission under its control, as does SWIFT. ${ }^{203}$

202. See, for example, Official Comment to UCC $\$ 7-104$, which, in relevant part, states: "A document of title is negotiable only if it satisfies this section." On German law, see Johannes C. D. Zahn, et al, Zahlung und Zahlungssicherung im Aussenhandel 168, 192 (Walter DeGruyter (Berlin), 6th ed 1986), where he quotes section 363 of the German Commercial Code for an exhaustive list of the categories of order paper (begebbares Orderpapier). This author states that an unlisted document cannot be turned into a negotiable document of title (Traditionspapier) by mere agreement of the parties and that such a transformation is only possible through legislation.

203. See text accompanying notes $56-70$. 


\section{The Legal Nature of the Paperless Letter of Credit and Bill OF LAADING}

Usually neither the issuance of paperless credits nor their advice, confirmation, negotiation, or payment is preceded by an agreement between the issuing bank and its SWIFT correspondents concerning each or all of these transactions. ${ }^{204}$ Some issuers may have line-of-credit facilities with their advising, confirming, or paying banks or may have agreed to act as correspondent banks, but most of the transactions described above are conducted among banks without pre-existing contractual commitments. Similarly, it would be highly unusual if a carrier were to enter into an agreement with each unknown transferee of the private key prior to the issuance of the receipt message. In the absence of preexisting agreements between the promisor and the promisee of a SWIFT letter of credit or a CMI electronic bill of lading, what makes the issuing banks' and the carriers' promises binding? Asked differently, what is the legal nature of these paperless promises?

The determination of the legal nature of these promises is of more than academic interest because it can help shape administrative and judicial decisionmaking in the absence of positive law guidance at a time when the volume and variety of paperless promises is growing rapidly. Since a bilateral contract is seldom entered into between the promisor and the promisee of a paperless letter of credit or electronic bill of lading, one may be tempted to conclude that the contract between these parties is unilateral-that is, one in which a promise or offer of a promise is issued in exchange for nonpromissory action. ${ }^{205}$ Yet unilateral (as well as bilateral) contracts presuppose both the need for the promisee's acceptance and the promisor's power to revoke his offer prior to its acceptance. ${ }^{206}$ In contrast, it will be recalled that the issuers of SWIFT's irrevocable letter-of-credit messages consider themselves bound as of the moment of the release of the messages to SWIFT, regardless of whether the promisees know about the promise or accept or rely upon it. Similarly, even though the new holder of the CMI private key must confirm his reception of the carrier's message of transfer, the carrier is bound by its

204. See Part I.A.4.

205. According to Corbin, "[t]he most common form of a unilateral contract is that in which the offeror makes a promise and asks some performance by the offeree in return, clearly indicating that the requested performance is the entire agreed exchange both for his promise and for the performance that he promises." Arthur L. Corbin, 1 Corbin on Contracts $\$ 70$ (West, 1963). The reason for the use of the word "traditional" in the principal text is that the Restatement has officially abandoned the traditional division of bilateral and unilateral contracts. See Restatement (Second) of Contracts \& 1 comment f (Am Law Institute, 1991) ("Second Restatement").

206. Section 42 of the Second Restatement states:

An offeree's power of acceptance is terminated when the offeree receives from the offeror a manifestation of an intention not to enter into the proposed contract.

Official Comment a, in turn, makes it clear that "most offers are revocable." See also Samuel Williston, 1 Williston on Contracts $\$ \S 55-56$ (Baker, Voorhis, 3d ed 1957) (Walter Jaeger, ed), and Corbin, 1 Corbin Contracts $\$ \S 38-39$ (cited in note 205). 
transfer message to cancel the current private key and to issue a new private key to the new holder.

Moreover, neither the paperless letter of credit nor the CMI electronic bill of lading can viably embody a promise whose enforcement depends upon unknown contractual rights, duties, defenses, or equities. For no banker would want to risk confirmation, negotiation, or payment of a SWIFT letter of credit only to be denied reimbursement because the applicant had failed to reimburse the issuing bank or because the beneficiary had sold unsatisfactory goods to the applicant. Similarly, no bank would want to extend credit to its applicant on the strength of an electronic bill of lading the description of goods on which by an agent of the carrier could be deemed ultra vires, thus rendering the bill unenforceable.

Hence, the paperless promises discussed in this article belong to the genus of "abstract payment undertakings" insightfully analyzed by Professor Goode in a recent essay:

[A] money promise which is independent of the transaction that gives it birth and which is considered binding when received by the beneficiary (or sometimes even when issued by the promisor) without acceptance, consideration, reliance, or execution in solemn form. The type of contract (if it be such) generated by the abstract payment undertaking fits neither the bilateral nor the unilateral model. It is not bilateral for no promise is given in exchange; nor is it unilateral in the ordinary sense, because its irrevocability does not depend on the performance, or even the commencement of performance, of a designated act or forbearance. ${ }^{207}$

After examining other possible theories of liability, Professor Goode finds that what makes these promises binding is mercantile usage. ${ }^{208} \mathrm{He}$ concludes that

any payment undertaking of a kind which by mercantile usage is treated as binding on receipt by the beneficiary will be so treated in English law where it conforms to the requirements for such usage and the usage can be shown to be reasonable in the sense of having a commmercial purpose which is not objectionable in terms of legal policy. ${ }^{209}$

This writer has also attributed the binding force of these promises to mercantile usage ${ }^{210}$ but would like to carry Professor Goode's inquiry further and identify the types of usage of paperless letters of credit. It should be remembered that commercial and banking usages, like weeds, spring up from unexpected places, emerging not only from the repeated observance of similar contractual and promissory undertakings but also from everyday practices under rules such as those found in SWIFT's Handbook or from CMI's rules for electronic bills of lading. The normative difference between

207. Roy Goode, Abstract Payment Undertakings, in Peter Cane \& Jane Stapelton, eds, Essays for Patrick Atiyah 209, 209 (Oxford U Press, 1991). For a similar view, see Kozolchyk, 9 Intl Encyclopedia Comparative $L$ at $\$ 12.3 .4$ (cited in note 5).

208. Goode, Abstract Payment Undertakings at 209, 225 (cited in note 207).

209. Id at 225.

210. See Boris Kozolchyk, On the State of Commercial Law at the End of the Twentieth Century, 8 Arizona J Intl \& Comparative L 1, 26 (1991) ("Hence, the ultimate source of law, on many issues formerly covered by traditional contract, is the usage of trade inspired by a pre-established, electronically programmed method of doing business."). 
the actual rules in SWIFT's Handbook or in CMI's rules for electronic bill of lading and a usage inspired by these rules is that while the usage may bind users regardless of proof of a contractual "meeting of the minds," contractual rules such as CMI's require such an agreement.

In addition, usages arise from everyday attempts to observe the SWIFT and CMI rules when these rules fail to specify how certain acts or transactions ought to be carried out and, knowingly or unknowingly, leave them to the parties' discretion. For example, neither the SWIFT nor the CMI rules preclude additional security arrangements agreed upon by their users for their own operations. Users may adopt whatever security arrangements they wish for transactions within their control as long as they do not conflict with those specified by SWIFT or the CMI rules. Similarly, since the CMI rules do not specify what language should be used in the carriers' receipt messages or in the shippers' or transferees' acknowledgments or confirmations, the parties are free to draft such messages as they will. Conceivably, over a period of time, these security arrangements and customary clauses could become sufficiently widespread to acquire the status of usages. Therefore, it is important so to classify the usage so that courts can, depending upon the type of usage involved, determine whether it is entitled prima facie to a presumption of validity and to dispensation with proof of reasonableness and consistency with legal (public) policy.

The first question in classifying the type of usage is determining who is supposed to be governed by the usage? If the usage is supposed to govern an open number of users or the public at large (public usages), it makes sense to require what has been required since classical Roman law: long-term observance (consuetudo longa) and the users' tacit consent to be bound (tacitus consensus populi, tacita civium conventio)..$^{211}$ If, however, the usage applies only to a closed number of users who are members of a commercial or trade association and who have knowledge of its transactions (associational usages), as is the case with SWIFT rules, it makes no sense to require that the usage be inveterate. SWIFT's usages, for example, could not qualify as inveterate because of their recency and changeability. Usages inspired by the SWIFT User Handbook do qualify as associational usages, however, and knowledge of SWIFT rules can be imputed to SWIFT users regardless of actual knowledge.

CMI rules, on the other hand, are intended to apply to an open number of users, including those ignorant of documents of title and maritime transportation communications. This feature is consistent with CMI's requirement that its application be agreed upon by the parties. Pari passu, CMI rule-inspired usages, as public usages, require proof of a sufficiently repeated practice, tacit consent, reasonableness, and consistency with public

211. Samuel Parsons Scott, Corpus Iuris Civilis, 1 Iustianan Digest D.1.3.32.1, 35 (Paulus Krueger, 1928). See also Adolf Berger, Encyclopedic Dictionary of Roman Law 411 (Am Philosophical Society, 1953) (voice Consuetudo). For a contemporary application of these requirements by French and German courts, see text accompanying notes 95-99. 
policy. In contrast, even if a SWIFT user can prove that he never read or expressly agreed to be bound by the SWIFT rules, his mere participation in the SWIFT network and his use of SWIFT messages and transmissions impute to him knowledge of the medium and compel him to follow the SWIFT User Handbook when it applies.

The second question pertains to the authorship of the usage. Is the usage in question a reflection of transactional behavior, or is it a nontransactional technical usage? Consider, for example, the relationship between the UCP and SWIFT. Many of SWIFT's rules incorporate UCP usages and are, therefore, transactional usages. Other SWIFT rules, however, are not, strictly speaking, banking usages but are rather the recommendations of computer and communication experts on how best to communicate transactional messages. As was discussed earlier, these technical usages impose duties of diligence upon SWIFT users but do not create transactional rights or duties within or without the SWIFT environment. ${ }^{212}$

The third and final question relates to the inevitability of the composition of the usage: does the usage in question necessarily require certain elements (necessary usage), or is it flexible enough to carry out its mission with equivalent or interchangeable elements (optional usage)? The task assigned to technical usages renders them more optional in character than transactional usages. Technical usages shape the means with which to communicate a message. If successful, they act as both the message's receptacle and its carrier. Thus, technical usages will determine the message's layout, syntax, and verification of authenticity as well as its routing. Their task lends technical usages a flexibility restricted only by the limitations of the medium, whether it be electronic or paper-based. For example, when the bill of exchange began to be used in large numbers in Renaissance Europe, the drawer's column was located at the bottom right and the acceptor's column at the bottom left of the letter-like document, but within the confines of this medium, the location of the columns was flexible enough to be interchangeable. Mutatis mutandis, the timing and location of passwords and electronic handshakes or the contents of the algorithm or of any other authentication or security device are restricted only by the limitations of EDI.

The task of transactional usages, on the other hand, is to bind one or more parties where neither contract nor official law establishes liability. As longdistance trade increased, some transactional usages acquired the task of expressing the promisor's liability and reassuring the promisee of its irrevocability. The liability expressed by such usages may be $a$ promise to pay or to deliver, a request that the recipient issue such a promise (accompanied by an expressed or implied promise of reimbursement), or an authorization for the issuance of a promise, payment of money, or delivery of an object (similarly accompanied by a promise of reimbursement). Among these transactional usages, those designed to reassure distant strangers that the promised money

212. See text accompanying note 55 for a discussion of transactional and system or network rights and duties. 
will be paid or the goods will be delivered must necessarily contain certain legal elements. In addition to the promisor's or issuer's known solvency and trustworthiness, the elements of reassurance are: (1) a clear expression of when, how, for how much or for what, and to whom the promisor is liable; (2) a standardized format, including reliable means for the verification of the authenticity of the message; (3) certainty that there will be no unexpected cancellation or revocation of the promise; and (4) a liability independent of underlying transaction claims, defenses, or equities. In the final analysis, the aim of such a usage is to support the circulation of promises the trustworthiness of which approximates that of "hard" currency.

The SWIFT paperless credit and the CMI private key procedure are intended to reassure distrusting and distant parties of the payment of a sum of money or of the delivery of specified goods. Once a promise of payment of money becomes as reassuring as SWIFT's letter of credit, it is "monetized"that is, quickly, easily, and cheaply convertible into cash or its equivalent by means of bookkeeping entries in the banks' nostro and vostro accounts. Not all the promises to pay money are monetized, and not all monetized promises are money's equal. In a scale of "moneyness," a promissory note by a party of unknown solvency ranks near the bottom, while a paperless promise to prepay or reimburse a SWIFT paying bank ranks near the top for reasons consistent with the presence of a necessary usage for monetized payments: SWIFT's letter-of-credit messages are, as a rule, issued by parties of known solvency and trustworthiness. They clearly specify the promisor's liability on a standardized text that includes devices for its own authentication. And the issuing bank's abstract promise of payment or reimbursment is established at the earliest possible time-that is, when the message is released to SWIFT.

If CMI-inspired usages on the transfer and encumbrance of shipped goods are to reassure third-party purchasers and creditors, including issuers of paperless credits, they will have to contain, mutatis mutandi, the preceding elements. In addition, their certainty and abstraction will have to be complemented by the notice provided by a centralized registry. And as public usages, they will not be binding until they have been observed for a sufficiently long period and are proven reasonable and consistent with public policy.

\section{Conclusion: The Future of the Electronic letter of Credit and Related Documents of TitLe}

Two viewpoints are frequently expressed on the future of the electronic letter of credit. The first regards the commercial letter of credit as a dying instrument soon to be replaced by direct electronic or network payment communications directly between buyers and sellers. ${ }^{213}$ A second viewpoint maintains that the paper-based letter of credit will be replaced by two types of

213. This view has been expressed at various ICC meetings held during 1990 and 1991 on the need to draft EDI rules for documentary credits by bankers who specialize in electronic fund transfers and in the adaptation of EDI to banking documentation. 
electronic credit.214 Type one will be the "default" credit, a credit payable upon certification that the parties did not settle the claimed debt by themselves. Although this credit is inexpensive and attractive to buyers, even its proponents admit that it will not be attractive to most sellers because it delays access to cash and requires surrender of the original documents when the seller attempts to collect directly from the buyer. Sellers will, therefore, insist on a second type of credit under which payment will be made by the issuing or confirming bank upon tender not of a group of paper documents, but of a single type of EDI message. This EDI message will state that the confirming bank has received, for example, an electronic bill of lading or waybill that on its face conforms with the terms and conditions of the credit, that it has paid or accepted a draft, and that it expects reimbursement. Documents transmitted electronically will not convey title to the goods; they will only acknowledge receipt of the goods and convey other requested information. These documents, therefore, will lack intrinsic value or merchantability.

Bernard Wheble espouses an intermediate and, in this writer's opinion, more plausible scenario. In a lecture delivered in Singapore in 1990,215 Wheble predicted that many documents as traditionally understood will cease to exist in the context of the paperless credit. ${ }^{216}$ At the same time, he warned that the replacement of the traditional, paper-based bill of lading would pose problems where the negotiability of the bill of lading was a requirement and that for a considerable period of time, paper-based bills of lading may have to continue to be used. He also warned of problems with respect to the presentation of electronic documents other than the bills of lading. Among these problems were the determination of the time and place of presentation, to whom the messages should be addressed, who should be their direct recipient, and whether the "originality" requirements should be preserved. ${ }^{217}$ According to Wheble, some of the these problems could be resolved by the parties' reliance on UNCID and appropriate user manual. ${ }^{218}$

This writer shares Wheble's view of an eclectic (paper-based and electronic) future. In addition, this writer is optimistic about the future of the letter of credit, whether as a paper-based or paperless promise, owing to the fact that distrust among trading partners is not likely to disappear soon. Some buyers and sellers, some borrowers and lenders will settle directly with each other, electronically or otherwise, but the remainder will continue to rely on the reassurance provided by the issuing and confirming banks (or other

214. This view was espoused during the meetings referred to in note 213 by some documentary credit bankers involved in the creation of paperless documents.

215. Bernard S. Wheble, Letter of Credit Practice-Uniform Customs and Practice for Documentary Credits (Singapore Conferences, 1990) (on file with the Documentation Center of the University of Arizona College of Law).

216. Id at 12.

217. "If the messages are sent direct to the seller by the service sector originator, they cannot be regarded as original messages, that is, as the real equivalent of original documents when passed 'second hand' by seller to bank." Id at 13.

218. Id. 
parties of known solvency and trustworthiness) of a fair, knowledgeable, and timely payment in exchange for the seller's complying documents or messages.

Documents, among their other attributes, are implements of reassurance. Some of the documents of the paperless credit, such as CMI's negotiable bill of lading, have intrinsic or merchantable value. Other documents, such as a certificate of origin or default, have only informational value. It should be remembered, however, that the bank's role in the letter-of-credit transaction is not only that of a paymaster, but also that of an escrow agent or fiduciary. The bank is entrusted both with the applicant's money or promise of reimbursement and with the beneficiary's complying documents. The bank is also a knowledgeable arbiter of documentary compliance. By enabling the bank to decide whether or not to pay on the basis of tendered documents, these documents help bridge the gap of distrust between the parties. In this role, a certificate of completion of a bridge issued by a trusted inspector could be as reassuring to the entity that contracted for the building of the bridge as is an on-board bill of lading to the buyer who needs possession of the goods by a certain date. Therefore, as long as buyers and sellers, principals and contractors, lenders and borrowers, and investors and promoters retain a healthy distrust of each other and continue to trust banks as judges of documentary compliance, there will be a need for the letter of credit's reassurance. This is particularly true because banks, unlike other financial intermediaries, can count on a worldwide network of trusted correspondents who act not only as promisors, examiners of documents, and paymasters, but also as carriers of valuable banking and trade information.

The transactional changes brought about by replacing a paper-based operative credit instrument with a teletransmission affect the form of the letter-of-credit transaction but not its underlying commercial function. The fact that the operative credit instrument among banks is now the SWIFT transmission, that the traditional notion of an "original" credit instrument is no longer central, or that authentication has replaced handwritten, stamped, or perforated signatures does not detract from the value of the bank's reassurance. On the contrary, some of the most vexing legal problems with promises of performance inter ausentes are now less troubling because of the technological advances connected with the paperless letter of credit. Consider, for example, the present ability of banks, regardless of location, to exchange telecommunications around the clock and to verify that a given message was received at a certain time, without errors, and in unaltered fashion. There is every reason to assume that the same capabilities will be available to applicants and beneficiaries. ${ }^{219}$

219. At the present time, European Economic Community banks are preparing drafts of EDIFACT messages that will allow applicants to communicate their request for issuances of letters of credit, much as has been done during the last decade by their U.S. counterparts. The difference between this EEC effort and the U.S. practice is that the messages and operating rules of the former will be standardized and will rely on the same software throughout the EEC. This software will be designed to enable issuing or confirming bank communications to the beneficiary including advises 
Considering the absence of technical difficulties with SeaDocs, ${ }^{220}$ the conclusions in Professor LoPucki's article in this symposium, ${ }^{221}$ and Professor Cumming's work in Canada, ${ }^{222}$ computer technology stands ready to do the job of supplying many, if not most, of the documents traditionally required by the paper-based letter of credit. ${ }^{223}$ The tasks awaiting the electronic documentary credit are quite significant. One of these tasks will be to reassure the buyers of debt and equity obligations in developing nationsparticularly in formerly socialist nations attempting to encourage the public's investment in privately issued securities. The success of the reassurance provided by standby letters of credit to buyers of these securities in the United States can be gauged by their annual volume of issuance, which, when last measured, exceeded $\$ 100$ billion. ${ }^{224}$

and confirmation. Interview of Terry J. Mitchell, Senior Manager Documentary Services, Lloyds Bank and British Bankers' Association Representative to the ICC Banking Commission (Aug 11, 1991). According to Mr. Mitchell, the electronic message for the documentary credit application form was to receive status 1 (for discussion among the member neations) on September 1, 1991. In addition to the normal documentary credit application language, the electronic message will contain information on which account to debit, and on forward currency contracts. The terms and conditions of the credit have been segmented for purpose of translation into EDIFACT language. Segmenation under EDIFACT is much more detailed and elaborate than with SWIFT messages. Each EDIFACT segment will contain smaller pieces of infomation to aid automation. Those parts of messages that cannot be uniformly stated in small segments will be "free formatted." It is anticipated that North American banks will, in due course, convert their proprietary packages discussed in text accompanying notes $164-170$ to EDIFACT, as SWIFT itself is in the process of doing.

220. See note 199 and accompanying text.

221. Professor LoPucki's own summary of his conclusion is that the "currently available computer technology is capable of overcoming most of the deficiencies identified . . . and creating a medium that communicates the contents of filed financing statements quickly, accurately and efficiently." Lynn M. LoPucki, Computerization of the Article 9 Filing System: Thoughts on Building the Electronic Highway, 55 L \& Contemp Probs 5, 6 (Summer 1992).

222. During the August 1990 Oxford University meeting of the International Academy of Commercial and Consumer Law, Professor Ronald Cuming, of the University of Saskatchewan, one of the world's leading authorities on computerized personal property registries, told this writer that under the computerized Canadian property registry systems that provide remote telephone access, it is possible to register interests in a registry and conduct a search of the registry from any place in the world that has reliable telephone access to the registry. In addition, arrangements are being made to permit a search of all registries from a single registry using that registry's remote access to the other registries. See Ronald C. C. Cuming, Computerization of Personal Property Security Registries: What the Canadian Experience Presages for the United States, 23 UCC L J 331, 336 (1991).

223. The argument is often heard that the traditional ocean bill of lading is being replaced by nondocuments of title, and if that is the case, why fight the marketplace? It is true that a large part of today's ocean carriage is documented with sea waybills and forwarders cargo receipts which are not documents of title. It is also true that air transport relies on air waybills which are, similarly, not documents of title. Nevertheless, these documents resulted from different marketplace considerations. A shipment by a consignor, who is also the consignee's parent company, can easily dispense with the document of title feature of the bill of lading. Similarly, a shipment of goods not likely to be resold while being transported, either because of the nature of the goods or because of the shortness of the journey, can, and often must, rely on nontitle transferring documents. Prominent among these are the sea or the air waybill which help expedite the delivery of the cargo to the named consignee. The same is not true, however, for other shipments such as of oil or grain. These shipments are usually resold to buyers in different parts of the globe, often repeatedly during one trading day. The spot as well as the futures market for these goods requires an electronic negotiable document of title that can facilitate both sales and secured transactions on a global basis.

224. On the need for the reassurance mentioned in the principal text, see Boris Kozolchyk \& James E. Byrne, Can Standbys and Guarantees be Harmonized?-Report on XVth Session of UNCITRAL 
Another significant task will be to help "globalize" the market for payments of principal and interest produced by financial standbys. Given the state of SWIFT technology, it is conceivable that banks in every corner of the globe could be examining the terms and conditions of "direct-pay" standbys to determine whether they wish to acquire payments provided by these standbys. They may also wish to participate in standby issuances either as coissuers, syndicators, or beneficiary-trustees.

The analysis of the rules that apply or purport to apply to the paperless letter of credit yields valuable lessons for the lawmaker. The first lesson is not to rush into lawmaking until all the relevant practices have been fully surveyed and understood. The confusion and uncertainty generated by Official Comment 3 to section 4A-104 of the UCC could have been avoided if the electronic and paper-based letter-of-credit payment and reimbursement practices had been taken into account when writing electronic fund transfer rules. The second lesson is that in writing definitions intended to govern future practice, not to rely solely on the outer limits of existing practice. This was the case with UCC section 5-103(1)(b)'s reference to paper in its definition of "document" 225 and may well be the case with definitions of electronic documents that include only formatted and standardized messages. The third and final lesson is to heed Rudyard Kipling's injunction in "Captains Courageous": "Things should ha' bin kep' sep'rate." The environment within which each set of rules is supposed to operate should determine the scope of application of the respective rules.

GROUP, in 7 Letter of Credit Update 6 (1991). According to statistics cited in this article, as of December 31, 1990, there were outstanding in the United States $\$ 104,213,546,000$ in financial standbys, $\$ 52,417,793,000$ in performance standbys, and $\$ 29,119,893,000$ in commercial letters of credit. Id at 11 .

225. UCC $\S 5-103(1)(b)$, in relevant part, states that “' '[d]ocument' means any paper including document of title, security, invoice, certificate, notice of default and the like" (emphasis added). This definition would prevent customs invoices and electronically transmitted bills of lading or sea waybills, among other contemporary types of electronic messages, from being regarded as the documentary components of "documentary drafts" or "demands for payment" under UCC art 5 (letters of credit). 
